\title{
LAS RELACIONES DIPLOMÁTICAS Y POLÍTICO-PARTIDISTAS ÍTALO-CHILENAS DURANTE EL GOBIERNO DE EDUARDO FREI MONTALVA
}

\begin{abstract}
RESUMEN
El ensayo explora los enlaces que se instauraron, durante la década de los sesenta del siglo pasado, entre la Democrazia Cristiana italiana y el Partido Demócrata Cristiano de Chile y, en términos generales, entre el gobierno italiano y el chileno, a través de una documentación de archivo que, hasta ahora, ha quedado bastante escondida. En este sentido, destacan los intercambios epistolares entre Eduardo Frei Montalva y algunos representantes y líderes del partido italiano (Fanfani, Moro, Bernassola y Freato). El ensayo se propone ofrecer temas de debate sobre las razones que movieron a la DC italiana a invertir muchos recursos -sobre todo financieros- y abnegación, en un escenario geopolítico lejano y, con excepción de Cuba, de competencia exclusiva de EE.UU.
\end{abstract}

Palabras clave: Italia, Chile, Estados Unidos, Internacional Demócrata-Cristiana, Eduardo Frei Montalva, Guerra fría, Democracia Cristiana.

\begin{abstract}
This work explores the links established between the Italian Christian Democracy and Chile's Christian Democrat Party during the sixties. Moreover, it considers the relationships between the Italian and Chilean governments, based on documentation that was, until now, unknown. Of particular interest is the regular mail correspondence between Eduardo Frei Montalva and some of the representatives and leaders of the Italian Christian Democracy (Fanfani, Moro, Bernassola and Freato). The article offers insights to debate about the reasons that encouraged the Italian Christian Democracy to invest financial resources and time in a distant Latin American geopolitical scenario, which was, with the exception of Cuba, part of United States sphere of influence.
\end{abstract}

Key words: Italy, Chile, United States, Christian Democrat International , Eduardo Frei Montalva, Cold War, Christian Democracy

Fecha de recepción: abril de 2009

Fecha de aceptación: agosto de 2009

* Doctor en Historia, Instituciones y Relaciones Internacionales de los Países Extraeuropeos (Universidad de Pisa). Profesor de Historia de América Latina, Facultad de Lenguas y Literaturas Extranjeras, Universidad de Nápoles L’Orientale. Correo electrónico: rnocera@unior.it 


\section{INTRODUCCIÓN}

No se puede aseverar que América Latina y particularmente Chile hayan sido el centro de la política exterior italiana durante las primeras dos décadas posteriores a la Segunda Guerra Mundial. Es más, la característica más sobresaliente fue un esencial desinterés demostrado por Italia, especialmente desde el punto de vista diplomático e institucional. Este fenómeno se debe a una mirada casi exclusivamente eurocéntrica, que dejó pocos márgenes de iniciativa con respecto a otros contextos geopolíticos ${ }^{1}$. Sin embargo, este desinterés no afectó la dimensión político-cultural que, por el contrario, como ha sido evidenciado por Luigi Guarnieri y Maria Rosaria Stabili², vivió una "época dorada" en los años sesenta-setenta (influenciada por la Revolución Cubana y por el breve gobierno de la Unidad Popular, que tuvieron gran repercusión en Italia), para después debilitarse en los años ochenta, hasta casi desaparecer en los noventa.

Generalizando, se puede decir que en este largo período (entre los años 50 y 80 del siglo pasado), además de a Europa (incluyendo al bloque comunista) y la coalición de las naciones más industrializadas (USA y Japón), el gobierno italiano apuntó casi exclusivamente a Medio Oriente y a los países de la cuenca del Mediterráneo, en el comprensible intento de proponerse como una potencia regional mediana $^{3}$ o, para usar las palabras de Di Nolfo, una "potencia de tamaño mediano pero autónoma"4. En este sentido, el gobierno italiano intentó adjudicarse, finalmente con éxito, un rol de intermediario entre el mundo occidental y el árabe, mediando en sus conflictos y tensiones. La centralidad de Europa y, en general, de las naciones más industrializadas en la conducción de la política exterior fue, en un cierto sentido, una elección forzada al comienzo de la segunda posguerra, tanto por la condición de país vencido como por las posteriores dinámicas continentales (y en un sentido más amplio internacionales), especialmente de los años 60 y 70; años caracterizados, como es sabido, por el reforzamiento de los organismos de integración regional nacidos en el decenio anterior y por los profundos cambios del sistema internacional.

1 Para un análisis más detallado de la política exterior italiana del período, sobre la cual existe un gran número de estudios, nos limitamos a señalar a Pietro Pastorelli, La política estera italiana del dopoguerra, Bologna, il Mulino, 1987; Ennio Di Nolfo, Romain H. Rainero y Brunello Vigezzi, L'Italia e la politica di potenza in Europa, vol. III, 1950-60, Milano, Marzorati, 1992; Richard J.B. Bosworth y Sergio Romano (eds.), La politica estera italiana (1860-1985), Bologna, il Mulino, 1991; Antonio Varsori, L'Italia nelle relazioni internazionali dal 1943 al 1992, Roma-Bari, Laterza, 1998; Giuseppe Mammarella y Paolo Cacace, La politica estera dell'Italia. Dallo Stato unitario ai giorni nostri, Roma-Bari, Laterza, 2006.

2 Luigi Guarnieri y Maria Rosaria Stabili, "Il mito politico dell’America Latina negli anni Sessanta e Settanta", en Agostino Giovagnoli y Giorgio Del Zanna, Il Mondo visto dall'Italia, Milano, Guerini e Associati, 2004, 228-241. Para analizar la producción editorial sobre América Latina hasta el final de los años setenta, ver, de Aldo Albònico, Bibliografia della storiografia e pubblicistica italiana sull'America Latina (1940-1980), Milano, Cisalpino Goliardica, 1982, y con respecto a Chile, las pp. 93-102.

3 Carlo Maria Santoro, La politica estera di una media potenza, Bologna, il Mulino, 1991.

4 Ennio Di Nolfo, "La politica estera italiana tra interdipendenza e integrazione", en Agostino Giovagnoli y Silvio Pons (eds.), Tra guerra fredda e distensione, Soveria Mannelli, Rubbettino, $2003,26$. 
Finalmente, es inevitable recordar los límites puestos por la confrontación Oriente-Occidente al eventual "expansionismo" italiano en áreas geopolíticas y mercados extraeuropeos, por lo menos hasta la primera mitad de los años ochenta. La Guerra Fría, de hecho, imposibilitaba un dinamismo excesivo de las potencias medianas en contextos geopolíticos "lejanos" -o sea que no fueran aquellos en los cuales estas estaban insertas geográficamente- si no era por "poder" de una de las dos superpotencias. En este sentido, Italia, miembro de la OTAN y aliada de Estados Unidos, no pudo ni quiso interferir excesivamente en el tablero latinoamericano, para no perturbar las estrategias continentales de Washington.

Sin embargo, aun con un objetivo de bajo perfil, diversos fueron los intentos realizados por la diplomacia y los gobiernos italianos para reafirmar los lazos con los estados latinoamericanos: entre el término de la Segunda Guerra Mundial y los primeros años de la posguerra, estos gobiernos se ensañaron en la recuperación de la credibilidad internacional y en la reanudación de las relaciones económicas y de los flujos migratorios 5 ; luego, entre los años cincuenta y sesenta, se insertaron en el marco de una ampliación de las relaciones entre Latinoamérica y Europa; hasta que, en los setenta, apuntaron hacia la supremacía de los intereses económicos por sobre los político-diplomáticos, pensando en un aumento de la atención hacia los intercambios comerciales y en las inversiones italianas. Esto significó que se volvieron prioritarios los intereses económico comerciales para la diplomacia italiana, así como el resguardo de las inversiones y el apoyo a las empresas presentes en la región, mientras que fueron sacados de agenda los asuntos más marcadamente políticos, por varios motivos: la inestabilidad del sistema internacional y el desarrollo de la confrontación entre las dos superpotencias, la evolución política del subcontinente con la llegada y mantención de los regímenes militares (y la preocupación de Roma por no repetir "un segundo Chile" ${ }^{\text {) }}$ y la crisis del sistema político italiano".

5 El incremento de la emigración en los primeros años de la segunda posguerra (después del estancamiento del período fascista), era la respuesta a la necesidad de alivianar el enorme peso del desempleo y volver a poner en marcha la economía, a través de las remesas de divisas de los emigrantes. Como en el pasado, también en aquel entonces América Latina fue una de las principales metas de la emigración italiana, si bien en el marco de una expatriación transoceánica, cuyos valores fueron mucho más contenidos con respecto a los flujos europeos. Acerca de la emigración italiana existe una gran producción historiográfica. Acá nos remitimos a Piero Bevilacqua, Andreina De Clementi y Emilio Franzina (eds.), Storia dell'emigrazione italiana, 2 vols., Roma, Donzelli, 2001 y, acerca de Chile, a VV.AA., Il contributo italiano allo sviluppo del Cile, Torino, Fondazione Giovanni Agnelli, 1993, y Maria Clotilde Giuliani-Balestrino, L'Italia fuori dall'Italia. Gli italiani in Cile, Genova, Bozzi, 2000.

6 Se hace referencia al enfriamiento de las relaciones ítalo-chilenas, como consecuencia de la decisión del gobierno italiano de no reconocer a la Junta Militar, cuestión estrictamente vinculada al asunto que involucró a todos aquellos chilenos que huían de la represión de la dictadura, que pidieron refugio a la embajada italiana en Santiago.

Este no es el lugar para analizar un decenio muy crítico de la historia italiana. Es suficiente recordar que estuvo caracterizado por la lucha armada del grupo terrorista de extrema izquierda de las Brigadas Rojas, que desestabilizó el sistema político italiano, de por sí "bloqueado" después de casi tres décadas de ininterrumpida gestión del gobierno de la Democracia Cristiana (DCI) y a causa de la imposibilidad de hecho para el Partido Comunista de asumir, a pesar de su consistente peso electoral y de las distancias que maduró en el tiempo hacia Moscú, la guía del país, por pertenecer Italia al bloque occidental (imposibilidad que siguió hasta la caída de los regímenes socialistas). Las Brigadas Rojas fueron responsables de atentados y de matar, o herir, a muchos periodistas, sindicalistas y hombres de Estado, entre los cuales se cuenta el líder y estadista democratacristiano Aldo Moro (1978). 
Pero aún con una directriz de política exterior tan estructurada, y a la que se ha hecho una breve referencia ${ }^{8}$, durante gran parte de la segunda mitad del siglo XIX Chile no fue un país que mantuviera con Italia relaciones político-diplomáticas o económicas privilegiadas dentro del tablero latinoamericano. De hecho, los gobiernos italianos se mostraron interesados en reafirmar los vínculos con naciones que tuvieran una inmigración italiana históricamente fuerte, como Argentina y Brasil, al igual que en la posguerra, y en profundizar los lazos con aquellas con las que los intercambios comerciales eran mayores, como era el caso de México y Venezuela (que también tuvo un gran flujo migratorio en los años cincuenta).

La interpretación sobre la marginalidad de Chile en la política exterior italiana en este período tiene validez independientemente de la fuerza política que se encontrara en el poder. Esta no varía ni siquiera en los años de gobierno de Eduardo Frei Montalva (1964-70), cuando los contactos entre las dos naciones se intensificaron gracias a los vínculos entre la Democracia Cristiana italiana y la chilena. Más que un fortalecimiento de los lazos diplomáticos y comerciales, que aun así existió, en ese período se asistió, de hecho, a una acentuación de los intercambios y contactos entre los partidos. Esencialmente, lo que mejoró y se profundizó sensiblemente fue la dimensión "político-partidista", por sobre la institucional.

Tanto es así que, en forma inédita, Italia y Chile se acercaron mucho en los años sesenta ${ }^{9}$. Como es sabido, en 1964, el Partido Demócrata Cristiano chileno (PDC) llevaba a cabo una larga fase de acercamiento al poder, logrando un gran éxito con la victoria de Eduardo Frei Montalva en las elecciones presidenciales. El rol de Italia, o para ser más precisos de la DCI, no había quedado para nada en segundo plano, ni en términos financieros ni político-ideológicos. Es más, los democratacristianos italianos podían mostrarse complacidos con el resultado, ya que en una vorágine de iniciativas y de esfuerzo, en un principio tímida y blanda pero en progresivo aumento, habían sido ellos quienes, en el ámbito europeo, habían confiado más en la reafirmación de las formaciones democratacristianas en América Latina y en la posibilidad de que llegaran al poder, proponiéndose como una alternativa sólida y duradera a los partidos tradicionales y, especialmente, a los de izquierda.

Aun así, el camino fue accidentado, por la presencia de una variedad de obstáculos generados por dinámicas políticas, tanto regionales como italianas. No fueron menores las incertidumbres de los democratacristianos ante la intervención en un escenario geopolítico lejano y en el cual Washington ejercía una influencia exclusiva (hasta la Revolución Cubana); y el hecho de que la acción

8 Para un análisis más detallado, véase Raffaele Nocera, "Italia y América Latina: una relación de bajo perfil, 1945-1965. El caso de Chile”, en Fernando Purcell y Alfredo Riquelme (eds.), Ampliando Miradas: Chile y su historia en un tiempo global, Santiago, RIL Editores, 2009.

9 No se encuentran textos acerca de las relaciones entre los dos países, exceptuando el trabajo fragmentado -y en su mayoría respecto a la comunidad italiana en Chile- de Silvia Mezzano Lopetegui, Chile e Italia. Un siglo de relaciones bilaterales, 1861-1961, Santiago, Ediciones Mar del Plata, 1995 . 
política de los partidos democratacristianos latinoamericanos se hubiera manifestado en contextos muy distintos.

Con respecto a este último aspecto, es necesario recordar que,

"nacidas de las mismas raíces y alimentadas por los mismos principios, la DC europea y la latinoamericana debieron realizar tareas esencialmente distintas, ya que distintas son las sociedades que motivaron su intervención. La DC europea tenía objetivos bien definidos, como los de crear o consolidar la democracia política que había sido aceptada en el pensamiento oficial de la Iglesia ${ }^{10}$ con extrema lentitud y suspicacia, y que generalmente había estado cargada con un significado sectario" ${ }^{11}$.

La DC latinoamericana, por otro lado, tuvo que enfrentar un camino lleno de obstáculos.

“Al principio hubo que precisar la ideología, definir los principios, crear una imagen y abrirse camino. La DC fue atacada duramente por la derecha, apartada cuando no condenada por la jerarquía eclesiástica, desestimada por las masas católicas y vista con desconfianza por los partidos de izquierda" 12 .

Por otro lado, a pesar de la difusión de un anticomunismo muy precoz y militante, en América Latina la lejanía relativa del peligro comunista -hasta la Revolución Cubana- y la existencia de formas de capitalismo muy incipiente, con estructuras agrarias rudimentarias, hicieron que la Iglesia Católica se identificara con los partidos conservadores (confesionales y clericales) ${ }^{13}$, lo que limitó y postergó el nacimiento de partidos de estampa democratacristiana.

Aunque el origen de los movimientos de base católica en América Latina yacía en los primeros decenios del siglo $\mathrm{XX}^{14}$, y aun existiendo desde abril de 1947 un organismo continental de enlace, la Organización Demócrata Cristiana de América $(\mathrm{ODCA})^{15}$, hubo que esperar hasta los años cincuenta para la reafirmación y el

10 Martin Conway, Catholic Politics in Europe, 1918-1945, London, Routledge, 1997; Stathis N. Kalyvas, The Rise of Christian Democracy in Europe, New-York-London, Cornell University Press, 1996.

11 Tomas Brèton, "I movimenti democristiani e la lezione del Cile", en Politica Internazionale 4, Roma, abril de 1975, 31 .

12 Ibid, 35.

13 Daniel H. Levine (ed.), Churches and Politics in Latin America, Beverly Hill-London, Sage Publications, 1980; Edward L. Cleary, Crisis and Change: the Church in Latin America Today, Maryknoll NY, Orbis Books, 1985; William H. Swatos Jr. (ed.), Religion and Democracy in Latin America, New Brunswick, Transaction Publishers, 1995.

14 Sin embargo, son dignos de nota solo aquellos de Uruguay y Chile. No hay que olvidar que en los años 30 y 40 manifestaron fuertes simpatías hacia el falangismo español y el corporativismo.

15 La ODCA nació en Montevideo, por iniciativa de exponentes del movimiento juvenil y estudiantil católico de Argentina, Brasil, Chile y Uruguay. Dos años después, siempre en la capital uruguaya, hubo un segundo congreso. En esta ocasión se definieron los propósitos de la organización, entre los cuales estaba el "de instaurar un tipo de civilización en que los valores del Cristianismo sean realmente vividos en las instituciones políticas, sociales y económicas". "El Congreso Demócrata Cristiano de Montevideo de 1949, Resoluciones", en Política y Espíritu 43, Santiago, agosto-diciembre de 1949, 27. 
desarrollo de la Democracia Cristiana, sobre todo en algunos países (cuyos ejemplos más representativos corresponden a Chile y Venezuela) ${ }^{16}$.

En las bases de este fenómeno encontramos la difusión de la doctrina social de la Iglesia, la expansión del electorado (sobre todo con la incorporación del voto femenino), la sustitución del conflicto religioso por el social y la necesidad, sobre todo de algunos sectores, de introducir reformas "estructurales", con las cuales poder contrastar la creciente amenaza del comunismo luego de la revolución castrista. Por lo tanto, solo luego de los años sesenta y tras la estela del Concilio Vaticano II, hubo niveles más altos de colaboración y convergencia entre la Iglesia Católica y la Democracia Cristiana latinoamericana, aunque en forma irregular y con variaciones de país en país.

A pesar de la referencia explícita a la doctrina social de la Iglesia, es oportuno recordar que los partidos democratacristianos no pueden ser equiparados con los católicos tradicionales latinoamericanos, ni especialmente con los grupos conservadores (de los cuales suelen derivar por divisiones y quiebres). De hecho, estos últimos, surgieron

"de la supuesta necesidad de defender los intereses de la Iglesia y la identidad religiosa, cultural y también económica de los católicos en un entorno hostil caracterizado por gobiernos militantemente liberales. En cambio, [los democratacristianos se atribuían] tareas bien definidas derivadas de la situación socioeconómica de Latinoamérica [con un] ímpetu de reforma social que distingue a los demócrata cristianos de los partidos conservadores y también del catolicismo aferrado por mucho tiempo a formas tradicionales de pensamiento y de conducta (especialmente la jerarquía eclesiástica)"17.

Son, por lo tanto, fuerzas políticas que compartieron su doctrina desde las principales encíclicas papales (particularmente la Rerum Novarum de 1891 y la Quadragesimo Anno de 1931) y fueron hondamente influenciadas por teólogos moralistas y filósofos sociales europeos, sobre todo por Jacques Maritain ${ }^{18}$ y Luigi Sturzo $^{19}$; se propusieron como un tercer camino entre marxismo y capitalismo; son

16 Joseph M. Macrum, Themes and Appeals of Christian Democracy in Latin America, Washington, Center for Research in Social Systems, 1967; Edward A. Lynch, Latin America's Christian Democratic Parties, Westport, Praeger, 1993; Scott Mainwaring y Timothy Scully (eds.), Christian Democracy in Latin America. Electoral Competition and Regime Conflicts, Stanford, Stanford University Press, 2003.

17 Wilhelm Hofmeister, La opción por la democracia. Democracia Cristiana y desarrollo político en Chile, 1964-1994, Santiago, Konrad Adenauer Stiftung, 1995, 31.

18 Acerca de la importancia de Jacques Maritain, véase Andrés Benaventura Urbina, "Jacques Maritain y la política chilena”, Estudios Sociales 34, Santiago, 1982, 127-144. Siempre acerca de los filósofos y pensadores (Jacques Maritain, Emmanuel Mounier, Louis Lebret) que influenciaron a los católicos y, posteriormente, a los democratacristianos chilenos, véase Corrado Corghi, L'ideologia democristiana e l'internazionale DC, Milano, Mazzotta, 1974, 237-270.

19 Sobre la vida, el pensamiento y el recorrido intelectual del sacerdote siciliano, existe una abundante producción que no es posible señalar aquí. Para una síntesis véanse G. De Rosa, "Luigi Sturzo", en Francesco Traniello y Giorgio Campanini (dir.), Dizionario storico del movimento cattolico italiano. 1860-1980, vol. II (I protagonisti), Casale Monferrato, Marietti, 1982, 614-24; el clásico texto, siempre de G. De Rosa, Sturzo, Torino, Utet, 1977; y el más reciente, Gennaro Cassini, Vittorio De Marco y Giampaolo Malgari (eds.), Bibliografia degli scritti di e su Luigi Sturzo, Roma, Gangemi, 2001. 
"partidos declaradamente católicos, pero con la aspiración de no ser confesionales [...] defienden la subordinación de los intereses económicos por sobre los espirituales y generales de la nación; prometen una ruptura con los aspectos negativos del pasado, proponiéndose contener los excesos del sistema capitalista" 20 ;

tienen una base electoral que está sobre todo en el mundo rural y entre la clase media urbana y los estratos populares urbanos; y, finalmente, en el centro de su reflexión y acción política se encuentran el comunitarismo y el corporativismo.

En lo que concierne más específicamente a la Democracia Cristiana chilena, sin poder explayarnos a causa del espacio ${ }^{21}$, es necesario al menos señalar que en la "Declaración de Principios" de 1957, la DC "se identificó como un partido que destacaba su estrecha relación programática con el cristianismo y su modo de actuar político derivado del mismo" 22 . Como es sabido, su principal ideólogo, Jaime Castillo Velasco, individuó particularmente tres "fuentes" de la Democracia Cristiana chilena: la filosofía cristiana, de donde derivaron los fundamentos éticos para el comportamiento de los cristianos en la sociedad y la realización del concepto de Maritain del "humanismo integral"; el conflicto social, que se explicitó en la crítica al modelo social del comunismo y al capitalismo liberal; y la doctrina social católica, que entregó las normas morales y las instrucciones prácticas de la acción política, todo esto en el marco de una clara y explícita diferencia entre la misión de la Iglesia Católica y la del partido, y de la certeza de que este último era un movimiento no confesional abierto también a los no católicos ${ }^{23}$.

Según Maria Rosaria Stabili, el Partido Demócrata Cristiano chileno "se ubica al centro del espectro político" 24 , prospectando un cambio radical de las estructuras políticas, sociales y económicas, en una etapa de la vida política nacional caracterizada por la "ruptura del consenso y de las alianzas al interior de los partidos" y por un "creciente conflicto político y social" 25 . La DC chilena se insertó en un marco político "tenso y polarizado", a causa de las repercusiones de

20 Manuel Plana y Angelo Trento, L'America Latina nel XX secolo, Firenze, Ponte alle Grazie, 1992, 211.

21 Ricardo Boizard, La democracia cristiana en Chile, Santiago, Ed. Nascimento, 1963; Edgardo Marín Riveros y Sofía Correa S., Historia del Partido Demócrata Cristiano, Santiago, Instituto Chileno de Estudios Humanísticos, 1981; Michael Fleet, The Rise and Fall of Chilean Christian Democracy, Princeton, Princeton University Press, 1985; Iván de la Nuez, La democracia cristiana en la historia de Chile, La Habana, Editorial de Ciencias Sociales, 1989; Fernando Suau Baquedano, La democracia en el PDC chileno: de la ambigüedad política a la crisis institucional: (1957-1970), Santiago, Universidad de Chile, 1989.

22 Hofmeister, op . cit., 52.

23 Para un análisis acabado de las tres "fuentes", léase Jaime Castillo Velasco, Las fuentes de la Democracia Cristiana, Santiago, Editorial del Pacifico, 1963; Eduardo Frei, Sentido y forma de una política, Santiago, Editorial del Pacífico, 1951, Pensamiento y acción, Santiago, Editorial del Pacífico, 1958 y La verdad tiene su hora, Santiago, Editorial del Pacífico, 1958.

24 Maria Rosaria Stabili, Il Cile. Dalla Repubblica liberale al dopo Pinochet (1861-1990), Firenze, Giunti, 1991, 106.

25 Ibid., 109. 
la Revolución Cubana (y de la respuesta de la Casa Blanca ${ }^{26}$ ) y, en forma no menor, a los cambios que se produjeron en la Iglesia Católica chilena, en razón del ya enunciado Concilio Ecuménico Vaticano II $^{27}$. Esto implicó un cambio drástico "de planes y posiciones [y] la presencia, al interior de la jerarquía eclesiástica chilena de hombres nuevos, capaces de gestionar la transformación de la institución" ${ }^{28}$. Entre el final de los años cincuenta y el principio del decenio siguiente, al interior de la Iglesia chilena comenzaron a prevalecer corrientes más reformistas y se evidenció una significativa renovación generacional de los dirigentes, con la sustitución de 14 obispos sobre un total de 28 , de los cuales, la mayor parte tenía una clara impostación progresista. Entre estos destacan los nombres de Emilio Tagle, Raúl Silva Henríquez -nombrados, en mayo de 1961, arzobispos de Santiago y Valparaíso, respectivamente- y, sobre todo, el del obispo de Talca, Manuel Larraín, los que mostraron una creciente atención por los problemas sociales, se pronunciaron decididamente a favor del compromiso de la Iglesia contra las disposiciones tradicionales y por los cambios estructurales de la sociedad chilena (especialmente de la reforma agraria) ${ }^{29}$ y, finalmente, abrieron camino a la caída de la cuestión prejuicial hasta ese momento existente hacia el Partido Demócrata Cristiano (con la consiguiente deserción del Partido Conservador) ${ }^{30}$. Fortalecida por el apoyo de la Iglesia y de la mayor parte de los católicos y, por otro lado, gracias a las reformas electorales aprobadas entre 1958 y 1962 que favorecieron la formación de un electorado masivo, la DC chilena se posicionó rápidamente como un "partido de síntesis" que mezclaba el "programa de modernización económica del país con los ideales de justicia y de desarrollo del pensamiento socialcristiano" 31 . $\mathrm{Su}$ mensaje político era interclase y

"tiene el objetivo de unificar el país en torno a un proyecto político único. La DC tiene una propuesta 'no capitalista' y 'no socialista', opta por un 'camino original', por una alternativa capaz de integrar lo positivo de los dos modelos. Nace así 'la revolución en libertad', un proyecto político de transformación económica y social radical, que según

26 Que se explicita durante la administración Kennedy, en el parcial abandono del intervencionismo y en la puesta en marcha de un plan económico continental, conocido con el nombre de “Alianza para el progreso", que asoció las ayudas de Estados Unidos (por un período largo) a las reformas estructurales, al desarrollo económico y a la democratización.

27 María Antonieta Huerta y Luis Pacheco Pastene, La Iglesia chilena y los cambios sociopolíticos, Santiago, Cisoc-Bellarmino, 1988; Michael Fleet y Brian H. Smith, The Catholic Church and Democracy in Chile and Peru, Notre Dame, University of Notre Dame Press, 1997; Enrique D. Dussel (coord.), Historia general de la Iglesia en América Latina, IX, Cono Sur (Argentina, Chile, Uruguay y Paraguay), Salamanca, Comisión de Estudios de Historia de la Iglesia en América Latina, 1993.

28 Stabili, Il Cile, op. cit., 109.

29 Aun antes de la reforma agraria, iniciada por el Gobierno de Eduardo Frei a partir del año 1967, Silva Henríquez y Larraín, en 1962, distribuyeron alrededor de 5.500 hectáreas de tierra (equivalentes a poco más del $10 \%$ de las tierra de propiedad de la Iglesia chilena), pertenecientes a la diócesis de Santiago y Talca, a los campesinos que trabajaban en ella. Sofía Correa et al., Historia del siglo XX chileno, Santiago, Editorial Sudamericana, 2001, 220.

30 Fue fundamental, en este sentido, la pastoral de septiembre de 1962, El deber social y político en la hora del presente, por medio de la cual se tomaban claras distancias con los conservadores, comprometiendo públicamente el programa de la Democracia Cristiana.

31 Stabili, Il Cile, op. cit., 114. 
los demócrata cristianos, debía elevar en la realidad nacional al conjunto de sectores sociales marginados y fuera del sistema político, sobre todo los trabajadores agrícolas, hasta ese entonces no sindicalizados, y las mujeres" 32 .

A lo que se ha señalado hasta ahora, se puede agregar que la Democracia Cristiana chilena -doctrinaria, integrista y con una arrogancia típica de estos movimientos -reconociéndose y proponiéndose como única y válida alternativa al socialismo y al capitalismo, y como vanguardia ilustrada, rechazó la formación de alianzas, oficialistas o electorales, con otras fuerzas políticas, apostando a lo que ellos mismos definieron como un "camino propio", cuya base implicaba que los postulados democratacristianos no debían ser influenciados mínimamente por otras propuestas políticas, ni habrían permitido ajustes ni compromisos políticos de ningún tipo.

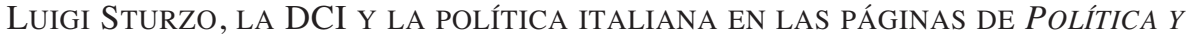 ESPIRITU}

El interés de la Democracia Cristiana italiana y la formación de vínculos con partidos latinoamericanos afines, sobre todo el chileno, se remontan a un período anterior a la primera mitad de los años sesenta -o sea, en los primeros años de la segunda posguerra- aunque el "diálogo interoceánico" se desarrolló por casi 15 años en forma episódica y heterogénea ${ }^{33}$, basado en iniciativas individuales y sin que la contraparte italiana -o por lo menos muchos de sus relevantes exponentes - tuviera una visión internacional de conjunto o elaborara un proyecto de largo plazo o un análisis preciso de los problemas y situaciones presentes en los diversos países latinoamericanos, de las perspectivas a mediano plazo y de los objetivos específicos. A pesar de esto, podemos fijar la segunda mitad de los años cuarenta como punto de partida de una tendencia nueva que se destacó a nivel de partido, tendiente a profundizar los vínculos interpartidistas, momento en el que comenzaron a instaurarse los primeros contactos entre personalidades políticas católicas italianas y chilenas. Hasta entonces, de hecho, no habían existido ocasiones de encuentro entre exponentes de esta corriente de los dos Estados, exceptuando el congreso de estudiantes católicos que tuvo lugar en Roma en 1933, donde tomaron parte numerosas delega-

32 Ibid., 114-115. No es casualidad que la "revolución en libertad" se basaba por sobre todo en cinco iniciativas de amplio respiro: la reforma agraria; la nacionalización gradual del cobre; la promoción popular; el voto a los analfabetos y la reforma del sistema educacional. Acerca del programa electoral y de gobierno de la DC chilena, véase George W. Grayson, El Partido Demócrata Cristiano Chileno, Buenos Aires, Editorial Francisco de Aguirre, 1968, 350-357; acerca del análisis de la realidad nacional y de la "crisis integral" del país en aquellos años, que estuvo en la base del programa de reformas, y sobre las intervenciones concretas del gobierno de Frei, véase Hofmeister, op. cit., 62-97.

33 En realidad, como ya ha sido señalado, no podía ser de otra manera, ya que los partidos democratacristianos o católicos aparecieron tarde en América Latina -el primero fue el COPEI venezolano (Comité de Organización Política Electoral Independiente) que nació en 1946- y las formaciones políticas de referencia del mundo católico eran los partidos conservadores. 
ciones latinoamericanas y algunas futuras personalidades de renombre de la Democracia Cristiana del subcontinente, entre ellas el venezolano Rafael Caldera $^{34}$ y el chileno Eduardo Frei Montalva ${ }^{35}$.

Fue muy importante la difusión en Chile de algunos textos de personalidades relevantes de la recién nacida DCI. En este sentido, la revista Política y Espíritu ${ }^{36}$ de la Falange Nacional, predecesora del PDC ${ }^{37}$, fue un lugar de encuentro privilegiado. Entre 1945 y fines del decenio siguiente se publicaron numerosos escritos sobre la política italiana y diversos aportes de figuras de primer plano del partido italiano, entre las cuales se encontraba Luigi Sturzo, fundador del Partido Popular Italiano (PPI). El periódico acogió siete artículos suyos, que habían salido ya en otras publicaciones ${ }^{38}$. Pero, a pesar de tratarse de recortes, a menudo breves, de textos que el sacerdote siciliano había escrito para otras entidades ${ }^{39}$, principalmente durante sus estadías en Londres y Nueva York ${ }^{40}$, y que expresaban su ansiedad a raíz del fascismo y la guerra, las preocupaciones por el futuro de Italia, la perplejidad hacia el ordenamiento internacional de la posguerra, la oposición al comunismo y su concepción de democracia y del rol de los partidos -y a pesar de que, en resumen, no se redactaron para el lector chileno-, estos representaron un importantísimo aporte para la formación político-ideológica de los jóvenes falangistas (al igual que los de otros teólogos, filósofos y pensadores católicos). Releyéndolos a distancia de años, y aun sabiendo que la corriente latinoamericana de la familia democratacristiana casi no existía en el horizonte político e intelectual de Sturzo, pareciera que los artículos tenían el objetivo de educar e instruir a un grupo político aún en pañales, constituyendo el primer gran aporte de la DCI a su contraparte chilena.

34 Presidente del Venezuela desde 1969 a 1974 y jefe indiscutido del COPEI

35 Grayson, op . cit., 117-118. Frei visitó también Bélgica y Francia (en París participó en algunos seminarios a cargo de Jacques Maritain). En Roma, empezó a crear un primer lazo con los ambientes del Vaticano (donde se encontró con el entonces cardenal Pacelli y monseñor Pisardo), que se hicieron más fuertes en los años siguientes, como lo muestran, solo para citar algunos ejemplos, las cartas enviadas a monseñor Montini y Pablo VI en 1945, en 1964 y en 1973, respectivamente (documentación en Centro de documentación Fundación Frei, en adelante CFF) y las audiencias especiales con los pontífices Juan XXIII y Pablo VI, en mayo y octubre de 1963, respectivamente (Cristián Gazmuri, Eduardo Frei Montalva y su época, Santiago, Aguilar, 2000, II, 542-545).

36 Política y Espíritu, cuyo subtítulo era Cuadernos mensuales de cultura política y economía social, vio la luz en julio de 1945. El director era Manuel Fernández Díaz, mientras que el Comité de colaboración estaba compuesto por Andrés Santa Cruz Serrano, Manuel Garretón Walker, Javier Lagarrigue Arlegui y Alejandro Maguet Paguéy.

37 La Falange Nacional nació en el año 1937 de una vertiente del Partido Conservador. Sobre esta formación política, véase Fernando Castillo Infante, La flecha roja, Santiago, Editorial Francisco de Aguirre, 1997. Una breve reseña de los valores que inspiraron la Falange y, en especial, las relaciones con las jerarquías eclesiásticas desde el nacimiento del movimiento hasta el año 1947 se encuentra en Maria Rosaria Stabili, "Il pensiero socialcristiano in Cile", en Andes 14, Roma, abril de 1992, 83-93.

38 La editorial, por el contrario, afirmó en más de una ocasión que se trataba de artículos escritos "específicamente para nuestros cuadernos".

39 El mismo discurso vale para todos los otros aportes - de autores italianos y no italianos- que serán señalados más adelante.

40 Después del largo paréntesis de Londres (1924-1940), Sturzo vivió en la ciudad estadounidense desde octubre de 1940 hasta el 1946. 
El primer artículo de Sturzo salió ya desde el segundo número. Su título fue "El Vaticano y Europa"41, donde el sacerdote siciliano ofrecía algunas interpretaciones sobre las relaciones que se habrían instaurado entre la Santa Sede y los Estados europeos luego de la guerra, desarrollando una extensa reflexión sobre las relaciones futuras entre el Vaticano y la URSS, y luego, entre el Vaticano y los partidos democratacristianos europeos. En lo que concierne a este último aspecto, no habría habido problema alguno, ya que los partidos ya habían adquirido una autonomía suficiente para desarrollar su actividad política ${ }^{42}$ y porque el Vaticano los habría apoyado, como a todos los partidos democráticos, en el proceso de reconstrucción luego de los duros años de la guerra.

Dos meses después, la revista publicó el segundo aporte de Sturzo ${ }^{43}$, mientras que en abril del año siguiente fue el turno del primer artículo dedicado íntegramente a la Democracia Cristiana italiana, titulado "Los demócrata cristianos de Italia"44. Usando como pretexto la visita de Alcide De Gasperi ${ }^{45}$ a Londres, algunos meses antes, la periodista y escritora de tendencia católica ${ }^{46}$ Barbara Barclay y Carter trazaba un marco histórico del partido desde sus orígenes hasta entonces, deteniéndose en los momentos más destacados y en las futuras perspectivas ${ }^{47}$. Es así que se desgranaban -a decir verdad en una forma un tanto conmemorativa- los primeros pasos del movimiento democratacristiano italiano, del Manifesto de 1900 al nacimiento del Partido Popular en 1919, desde los éxitos electorales de los primeros años a la clandestinidad durante el fascismo, para terminar con el programa de la DCI para la Italia de la posguerra (preferencia por la forma republicana, reforma agraria, etc.). En el mismo número apareció luego, también, el primer comentario sobre la política en Italia, en "Panorama Internacional", donde se hablaba acerca del discurso pronunciado por De Gasperi en el Congresso della Federazione Universitaria dell'Azione Cattolica.

El artículo de Barclay y la nota recientemente señalada representaron poco más que una antesala con respecto al mejoramiento que se logró poco después. De

41 Luigi Sturzo, "El Vaticano y Europa”, en Política y Espíritu 2, agosto de 1945, 43-49.

42 "Cualquiera que haya de ser el futuro de Italia, y Francia, los grupos católicos democráticos de esos países ya no representarán el viejo clericalismo con su oposición sistemática a las modernas instituciones democráticas y parlamentarias y con su temor al progreso social de las clases trabajadoras [...] Los partidos de inspiración demócrata-cristiana no solicitan de la Iglesia apoyo ni favores [ellos] se abstendrán cuidadosamente de convertirse en fuerzas de choque en nombre de la Iglesia”. Ibid., 48.

43 Luigi Sturzo, "La primera crisis de post-guerra", en Política y Espíritu 4, octubre de 1945, 105-112. Se enfrentaban, principalmente, los asuntos del derecho de veto de las cinco grandes potencias en el seno del Consejo de Seguridad de las Naciones Unidas y de la constitución de las esferas de influencia, que Sturzo condenaba de forma categórica.

44 Barbara Barclay y Carter, "Los demócrata cristianos de Italia", en Política y Espíritu 10, abril de 1946, 109-111.

45 Sobre De Gasperi - uno de los padres fundadores de la DCI, y por lo demás, entre los más importantes políticos de la historia republicana italiana-, véase la reciente y completa biografía política de Piero Craveri, De Gasperi, Bologna, Il Mulino, 2006.

46 Además intérprete y traductora de Sturzo durante su exilio en Londres.

47 Según la autora, "todo indica que puede convertirse en el partido más poderoso del país" y "la lucha por el primer puesto entre los Cristianos Demócratas y los socialistas y comunistas unidos, será dura. Pero no cabe duda que la democracia cristiana es y será una fuerza de gran envergadura en la vida política de Italia". Barclay y Carter, op . cit., 111. 
hecho, solo dos meses después, Política y Espíritu publicó otro artículo de Sturzo. Su título era "Partidos y país" 48 , y reflexionaba sobre la importancia y el rol de los partidos en la vida política italiana y europea, concentrándose sobre todo en dos aspectos: el sistema partidista y la base social y electoral de las formaciones políticas. El sacerdote siciliano declaraba su preferencia por el pluripartidismo -sobre todo en la situación particular vivida entonces en Italia ${ }^{49}-$ y por las formaciones interclase. En este último caso, con una invitación implícita al grupo al que pertenecía, Sturzo destacaba la necesidad de capturar y conquistar a la clase media, considerada como uno de los sectores "más castigados por la guerra y la inflación" y que se "dirigen a los partidos extremos o se hallan en el tropel de los descontentos y de los rebeldes", y manifestaba, con una implícita referencia a los socialistas y comunistas, su oposición hacia los partidos de "una sola clase [que] se inclinan a identificar los intereses del país con los de la clase que representan o a subordinar los intereses de las demás clases a los de la propia clase".

En su cuarto aporte, titulado "Sobre la democracia" ${ }^{50}$, Sturzo tocaba los conceptos de democracia y libertad y, para ser más precisos, sobre la "disputa [de] si es posible que existan 'libertad' sin democracia y 'democracia' sin libertad". En un artículo carente de referencia a Italia, se destacaba que:

"la democracia es verdaderamente tal, únicamente, cuando la participación en el poder es un derecho inalienable del pueblo, o de aquella entidad que en un determinado momento histórico puede llamarse el verdadero pueblo, que goza, en consecuencia, de una soberanía que él ejercita directamente o por medio de sus representantes. De aquí que la libertad esté comprendida implícitamente en la noción de democracia. Una democracia en la cual no existe libertad, no es sino una democracia en apariencia”.

Sturzo se refería solo una vez a la Democracia Cristiana, destacando que "hacia el fin de siglo [...] aceptó la democracia de los países libres como punto de partida para el desarrollo de una concepción social sobre la base de una colaboración de clases".

Tres meses después, el fundador del PPI entraba de lleno en la realidad italiana, aunque fuera solo para ilustrar las "tendencias ideológicas y filosóficas en Italia" 51. En el artículo se describían concisamente las corrientes ideológicas y filosóficas difundidas en Italia entre 1800 y 1900: liberal, republicana, radical, democrática, socialista, comunista y naturalmente democratacristiana. La conclusión del artículo contenía un duro ataque al comunismo y a la desagradable constatación que

48 Luigi Sturzo, "Partidos y país", en Política y Espíritu 12, junio de 1946, 159-163. Hay que señalar que en este número aparecieron también dos pequeñas notas tituladas "Los demócrata cristianos a favor de la república en Italia" y "Gabriela Mistral defiende Italia".

49 Sturzo evidenciaba que, "para un país que ha estado veintiún años bajo la dictadura y obsesionado por el partido único, esta florescencia de partidos es un primer respiro de aire libre" y que "la multiplicidad de los partidos es en Italia [...] una exigencia incoercible". Ibid., 160.

50 Luigi Sturzo, "Sobre la democracia”, en Política y Espíritu 15, septiembre de 1946, 65-69.

51 Luigi Sturzo,"Tendencias ideológicas y filosóficas en Italia", en Política y Espíritu 18, diciembre de 1946, 169-172. 
"hoy la atracción ideológica más fuerte de Europa proviene del comunismo, no porque los europeos crean en un paraíso comunista, sino como reacción contra el tipo de capitalismo que creen se encuentra a la raíz del desastre actual, y también como resultado de la simpatía hacia Rusia, cuyas hazañas y valor dan un matiz romántico al más prosaico de todos los sistemas sociales".

El sexto artículo de Sturzo salió luego de un año y medio, y se centró en el movimiento democratacristiano en Europa, en sus orígenes, en sus principales inspiradores y pensadores, en los caracteres y los elementos teóricos ${ }^{52}$. El autor se detenía primeramente en la distinción que debía hacerse entre la DC y el movimiento social de los católicos (movimiento "en favor de las clases obreras que sigue las enseñanzas papales, de las cuales las más conocidas son las dadas en las encíclicas Rerum Novarum de León XIII y Quadragesimo Anno de Pío XI”) y entre la primera y la Iglesia Católica; luego, en algunos problemas filosóficos, ideológicos y metodológicos que el movimiento aún no había resuelto completamente (sin escatimar en críticas también hacia la Iglesia Católica y, sobre todo, a algunas corrientes de pensamiento católico y a los "escritores que han sido hombres de Iglesia”). Sturzo indicaba, además, los pasos a seguir para que los partidos democratacristianos pudieran manejar el proceso de renovación y de reconstrucción política, económica y social de la posguerra.

En el último artículo publicado por la revista (casi un año y medio después del anterior $)^{53}$, Sturzo se despedía del público chileno con una reflexión sobre el concepto de "Estado de Derecho", sobre el problema de la moral y la política y sobre la centralidad e importancia de la "persona humana". Queriendo hacer un balance de su aporte a los futuros democratacristianos chilenos, es necesario señalar que Política y Espíritu escogió y publicó principalmente textos de alto perfil, de corte filosófico y doctrinario, donde raramente había referencias a la realidad política italiana y menos aún se señalaba el programa político o de gobierno de la DCI, su orientación de política económica o su visión del mundo de la posguerra. En síntesis, se seleccionaron artículos en los cuales Sturzo se mantenía al margen del debate político contingente y, por el contrario, concentraba su atención en asuntos exquisitamente teóricos.

Sin ir más lejos, en esos años no faltaron en el "cuaderno" de la Falange informes de la vida política italiana y, sobre todo, sobre el rol y los objetivos de la DCI. Tenemos el caso, entre 1947 y 1951, de dos escritos del famoso jurista Fernando Della Rocca y de Máximo Pacheco Gómez. En el primero, el autor ilustraba los principios directivos de la $\mathrm{DCI}^{54}$ y la importancia de la presencia de esta última en el panorama político italiano de la posguerra. Basándose sobre todo en las "enseñanzas pontificias" 55 , Della Rocca indicaba los postulados fundamenta-

52 Luigi Sturzo, "Democracia cristiana”, en Política y Espíritu, 32, mayo de 1948, 59-69.

53 Luigi Sturzo, "Política y moralidad", en Política y Espíritu 54, diciembre de 1950, 207-213.

54 Fernando Della Rocca, "Principios directivos de la Democracia Cristiana en Italia", en Política y Espíritu 21, abril de 1947, 111-114.

55 Es decir, las encíclicas Rerum Novarum de León XIII, Quadragesimo Anno, Casta Connubi, Divini Redemptoris de Pío XI y Sertum Laetitiae de Pío XII. 
les del partido, sobre todo la importancia de la familia y del vínculo matrimonial y "la justa armonía del principio de la libertad con el de autoridad". En el ámbito económico, subrayaba la importancia del factor moral ${ }^{56}$ y de la apropiada remuneración del trabajo (según el principio del salario familiar y de "que el capital no tienda a acumularse en perjuicio de los obreros"57); la defensa de la propiedad privada, aunque limitada por el bien colectivo y al superior interés público; una distribución de la riqueza justa y ecuánime ${ }^{58}$; y la precisión de los límites y las funciones del Estado. En este último caso, refiriéndose explícitamente a la encíclica Quadragesimo Anno, Della Rocca destacaba que el Estado

"debe defender la colectividad y ejercitar el orden en las variadas relaciones sociales, pero nunca entrar en todas las formas de la vida social sustituyéndose a los principios que la determinan. La sociedad familiar, la religiosa, la profesional y la económica son expresiones primordiales y autónomas de la sociedad humana y de consiguiente, no solo merecen todo respecto del Estado, sino el derecho de pedir y obtener que el Estado les asegure su justo desarrollo".

Pacheco Gómez, por otro lado, detalló más la vida política italiana del momento. Se generó la ocasión a partir de una estadía en Italia de un año, mientras perfeccionaba sus estudios de Derecho, gracias a una beca del gobierno italiano. En el artículo titulado "La Italia de hoy"59, ofreció así sus impresiones sobre algunos de los aspectos que más lo habían impresionado del país. Surgió de aquello una visión elogiable de las virtudes italianas, del pueblo, del sistema político, de la sociedad y, considerando sus intereses, del estado de los estudios jurídicos en las universidades y de los "maestros" del Derecho italiano.

La parte más interesante, para los fines del presente ensayo, es la descripción de los partidos políticos que, en realidad, se reducía al comunista y a la DCI, desde el momento en que todos los otros tenían una "influencia secundaria". Si el primero era claramente considerado como un problema por Pacheco Gómez -aunque el autor expresara juicios positivos hacia Palmiro Togliatti ("hombre de excepcional capacidad intelectual y organizativa") y, en general, hacia dirigentes y parlamentarios-, el segundo, era objeto de consideraciones más favorables, aunque no faltaran críticas ácidas. Con lenguaje y estructura a ratos casi periodística, el autor destacaba que

"la fuerza de este partido está constituida por el sentimiento anticomunista del pueblo italiano, y su debilidad, por la heterogeneidad de sus militantes, que, si bien es cierto,

56 "En el campo propiamente económico, la democracia cristiana proclama la inconsistencia de todo sistema político que repose sobre el principio de la disociación del elemento económico del elemento moral". Ibid., 112.

57 A partir de esto, Della Rocca extraía "la valorización de las formas de asistencia y previsión social previstas en el programa de la democracia cristiana, para la tranquilidad del obrero y la capacitación de su trabajo económico, repudiando toda forma de despotismo económico". Ibid., 113.

58 La DCI "repudia como dos excesos dañinos tanto el sistema de la economía liberal como el de la colectiva". Idem.

59 Máximo Pacheco Gómez, "La Italia de hoy”, en Política y Espíritu 55, marzo de 1951, 49-58. 
están unidos por una común filosofía espiritualista, frente a la solución practica de los problemas económicos sus opiniones se dividen [...] esta falta de unidad frente al trabajo social hace que la acción de este partido no sea lo suficientemente dinámica, lo cual es hábilmente aprovechado por los comunistas para fomentar huelga o tomas de posesión de terrenos".

El autor se detenía luego en las tres corrientes presentes al interior de la Democracia Cristiana italiana, y era la primera vez que el lector de la revista participaba en ello:

"una está constituida por un grupo de intelectuales de avanzada, como Giorgio La Pira, que son los que constituyen el motor del partido, lo impulsan a la acción y tienen proyectos concretos de reformas sociales, pero que están en minoría; otra es la que representa la tradición reaccionaria, que aporta el dinero y la influencia y está constituida por los ricos industriales de Lombardia; y una tercera fracción es la que encabezan el premier Alcide De Gasperi y el hombre fuerte del gobierno, el Ministro del Interior Scelba, que tiene mayoría numérica y realiza habilísimas maniobras para conservar la unidad".

Sin embargo, a pesar de estas divisiones, no era previsible una división del partido, "por lo menos en fecha próxima". Seguía, finalmente, la opinión sobre la presunta influencia y sobre las intervenciones de la jerarquía eclesiástica y del Vaticano en la administración interna y en las decisiones de la DCI. Entonces, para Pacheco Gómez,

“intervención directa no existe, pero sí apoyo o colaboración indirecta, que se traduce en que la jerarquía y el clero en general miran con buenos ojos a este partido y lo ayudan, especialmente en sus campañas anti-comunistas, y tanto, que, por ejemplo, la campaña de propaganda anti-comunista está a cargo, casi exclusivo, de la Acción Católica".

Con respecto a la oportunidad de la colaboración, el autor la consideraba "aceptable", ya que es "eminentemente doctrinal y defensiva, en contra del Partido Comunista más fuerte, organizado y beligerante de Europa, y porque es apoyo ideológico y no intervención en la acción de gobierno".

El año siguiente, en el marco de un reportaje de cuatro capítulos titulado "El movimiento demócrata cristiano en Europa" ${ }^{60}$, se publicó un artículo del escritor y ensayista francés Maurice Vaussard en el que se destacaba el estado de salud de la

60 Los artículos salieron todos originalmente en el semanal francés Témoignage Chrétien, con el objetivo de entender si la "crisis" por la que pasaba en aquel período el movimiento democratacristiano era de "decadencia o de crecimiento". El primero, cronológicamente, fue el de Jules Gérard-Libois, "Bélgica. Una política prudente, pero sin genio, al servicio del régimen”, en Política y Espíritu 74, agosto de 1952, 230-232; siguió el de Jacques Fauret, "Francia. Si el M.R.P. no existiera ¿Habría que inventarlo?", en Política y Espíritu 76, septiembre de 1952,8-11); el artículo acerca de Italia sobre el cual nos detendremos dentro de poco; y el de Walter Dirks, "Alemania. La Unión Demócrata Cristiana: un coloso con los pies de barro", en Política y Espíritu 78, octubre de 1952, 5-10. 
DC italiana ${ }^{61}$. Se trataba del primer análisis serio y crítico sobre las vicisitudes del partido, sobre todo entre los años 1951 y $1952^{62}$. Vaussard enfrentaba sin rodeos las divisiones internas, las dificultades del gobierno en el campo de la política económica y social (especialmente las concernientes a la reforma agraria), la centralidad y el rol de De Gasperi, las perspectivas futuras y el modo en el cual el partido enfrentaría las elecciones de 1953.

Luego de dos meses de la publicación de Vaussard, Política y Espíritu publicó el primer y único escrito de Alcide De Gasperi ${ }^{63}$, en el que el líder democratacristiano se preguntaba si, derrotado el fascismo, "la lección había sido comprendida y sobre todo si las nuevas constituciones y las directivas posbélicas de los gobiernos habían tenido en cuenta, en medida suficiente, el mortal peligro pasado por la democracia”, para llegar a la (conocida) conclusión de que solo la influencia del cristianismo sobre la democracia habría podido alejar el peligro de una nueva vertiente autoritaria: "Solo el Cristianismo, ennobleciéndonos para las conquistas futuras, puede impedir que una impaciencia brutal no domine, frente a la lentitud y las debilidades del hombre".

Luego de este aporte de De Gasperi, a quien la revista dedicó dos artículos para recordar su partida en agosto de $1954^{64}$, hubo que esperar seis años para poder leer otro texto sobre un político democratacristiano italiano, por demás destacado, como fue Mariano Rumor ${ }^{65}$. Se trataba de una entrevista ${ }^{66}$ concedida por este último al periódico de la DCI Il Popolo, con ocasión del Segundo Congreso Internacional Demócrata Cristiano de São Paulo, en septiembre de 1957. El delegado de la DCI compartía la confianza de sus pares latinoamericanos en que "la Democracia Cristiana sudamericana afirmará su propia fuerza y llegará a ser cada vez más la intérprete más eficaz de la difundida conciencia cristiana de aquellos pueblos", aun confesando que antes de dejar Italia, no habría esperado encontrarse "ante una

61 Maurice Vaussard, "Italia. 'Somos un partido de centro que va hacia la izquierda'. Este pensamiento de De Gasperi ¿Es compartido por todos sus colaboradores?”, en Política y Espíritu 77, septiembre de 1952, 8-11.

62 Hay que señalar que los mejores artículos acerca de Italia publicados en aquellos años en Política y Espíritu no fueron firmados por autores italianos, sino por extranjeros. Es el caso, además del recién citado de Vaussard, del largo reportaje del periodista francés Pierre Frederix, "Perspectivas italianas" (Política y Espíritu 69, marzo de 1952, 69-79), publicado en el mes de noviembre de 1951 en el diario Le Monde y del cual la revista publicó un amplio extracto. Frederix ofreció un cuadro clarificador sobre la situación italiana del período y un análisis detallado del sistema político, social y económico, del rol de los principales partidos, sin dejar de lado el peso todavía muy fuerte del desempleo, el rol del Vaticano, el incremento de la emigración, las incertidumbres en materia de reforma agraria, la ayuda estadounidense y la acción de la política exterior.

63 Alcide De Gasperi, "Las bases morales de la democracia", en Política y Espíritu 81, noviembre de 1952, 4-7.

64 Ignacio Palma Vicuña, "Homenaje a Alcide De Gasperi”, en Política y Espíritu 121, octubre de 1954, 31-32; y Emilio Komar, "El perfil humano de Alcide De Gasperi”, en Política y Espíritu 131, abril de 1955, 16-20.

65 Mariano Rumor fue un exponente de avanzada de la DCI del Veneto - uno de los feudos del partido-, secretario político del partido (1964-68), ministro varias veces (Agricultura, Interior, Relaciones Exteriores) y presidente del Consejo (1968-70 y 1973-74).

66 "La democracia de América vista por Mariano Rumor", en Política y Espíritu 195, enero de $1958,12-14$. 
fuerza política como la que encontré en el contacto directo". Luego de haber tocado las diversas realidades locales (entre las cuales naturalmente también la chilena ${ }^{67}$ ), Rumor era un convencido de que las formaciones democratacristianas latinoamericanas estaban destinadas

\begin{abstract}
"a aumentar progresivamente su fuerza electoral: la línea programática coincide con la convicción profunda y la adhesión del más ancho núcleo del pueblo, la conciencia nacional de cada partido es alta y universalmente reconocida, abierta la visión de la colaboración y sus representantes son universalmente respetados y admirados por su alta conciencia moral, su rectitud y su preparación. Creo que continuarán expandiéndose, particularmente entre los sectores medios y las clases populares, y serán en el porvenir una fuerza de progreso libre y de resistencia a los extremismos totalitarios".
\end{abstract}

Finalmente, el político italiano destacaba con orgullo que la DCI "es objeto de admiración y de afecto" y que los democratacristianos latinoamericanos "ven en la experiencia decenal de la D.C. casi un modelo sobre el cual orientar su experiencia política [...] La popularidad de nuestros hombres políticos es grandísima en todas partes". En resumen, ateniéndose a los dichos de Rumor, la debilidad de las formaciones democratacristianas latinoamericanas y la indiferencia mostrada por su contraparte italiana (y europea) hacia su futuro (además del escaso conocimiento del recorrido que habían cumplido hasta entonces), eran un lejano recuerdo, y al final de los años cincuenta existían ya las condiciones para una estrecha y fructífera colaboración y para un prometedor futuro del movimiento democratacristiano en América Latina.

\title{
LAS AFINIDADES ELECTIVAS
}

El real logro se tuvo a partir de principios de los sesenta. En este sentido, no fue secundario el rol ejercido por la Unión Mundial Demócrata-Cristiana (UMDC) para unificar los vínculos, más allá de la matriz ideológica común ${ }^{68}$. La UMDC nacía durante la III Conferencia intercontinental de los democratacristianos ${ }^{69}$, realizada en Santiago entre el 27 y el 30 de julio de 1961, y cuyo tema fue "Las condiciones políticas, sociales y económicas de los continentes y el desarrollo de la Democracia Cristiana"70. En un cierto sentido, se cerraba una antigua aspiración

67 "En Chile la DC, ha nacido de la necesidad de dar al país un partido cristiano de vanguardia social". Ibid., 12.

68 Véase el texto de Roberto Papini, L'Internazionale DC. La cooperazione tra i partiti democratici cristiani dal 1925 al 1985, Milano, Franco Angeli, 1986, que resulta muy útil para describir el recorrido del rol y de los aspectos organizativos y técnicos de las organizaciones regionales (la americana ODCA y la europea Nouvelles Equipes Internationales - NEI) y de la UMDC.

69 La I y la II conferencia, de alguna manera preparatorias de la de Santiago, se habían realizado en París (8-9 de noviembre de 1956) y en Bruselas (9-10 de julio de 1958), respectivamente.

70 Papini, op . cit., 289. Véase también el comentario de redacción en Política y Espíritu ("La III Conferencia Mundial DC. Nace una fuerza mundial", $\mathrm{N}^{\circ} 263$, agosto de 1961, 28-32; $\mathrm{N}^{\circ} 264$, septiembre de 1961, 43-44; No 265, octubre de 1961, 40-48) y el de la revista Mensaje (Cristián Zegers, "Congreso mundial Democratacristiano", N ${ }^{\circ} 102$, septiembre de 1961, 385-386), fundada en octubre de 1951 por el padre Alberto Hurtado. 
de Luigi Sturzo, de crear una organización internacional de partidos de inspiración cristiana $^{71}$, aunque, en honor a la verdad, la constitución de la UMDC fue una iniciativa principalmente de los latinoamericanos, quienes tenían la intención de crear un organismo de unión entre las estructuras regionales. No es trivial, de hecho, que los europeos hubieran enviado a Santiago a personalidades de segundo plano o poco representativas (la delegación de la DCI, sin embargo, estaba presidida por el vicesecretario nacional Gian Battista Scaglia), mientras que el año siguiente, se mostraron mucho más interesados y partícipes en el $1^{\text {er }}$ Congreso Mundial de la Unión Internacional de Jóvenes Demócrata Cristianos, que tuvo lugar en Caracas (del 8 al 15 de mayo de 1962) 72. $^{2}$.

El proceso de cooperación internacional entre los partidos democratacristianos, a pesar de la gran novedad que representaba, no fue fácil y sufrió la resistencia de las formaciones europeas -no de la italiana- para la profundización de los vínculos con realidades lejanas y consideradas periféricas ${ }^{73}$. No es casual que, a distancia de dos años de la reunión de Santiago, el holandés Karl Josef Hahn -uno de los más sensibles a las realidades extraeuropeas entre los dirigentes de la DC de Europaen un breve artículo publicado en el trimestral Civitas $^{74}$, incentivara a los democratacristianos europeos a hacer más, considerando que se requería colaboración urgente, tanto por las condiciones político-sociales y económicas vividas en esos años por los países africanos (inestabilidad e incertidumbres poscoloniales) y latinoamericanos (subdesarrollo y militarismo), como por el cada vez más amenazante desafío del comunismo internacional (en América Latina bajo la imagen del castrismo). Hahn realizaba una severa crítica a las formaciones del viejo continente, poco atentas a la proyección internacional del movimiento católico (salvo en Europa) y las acusaba de haber subestimado hasta ese momento, y de seguir haciéndolo, las experiencias políticas cristianas en África y América Latina.

71 Sobre los intentos hechos por Sturzo en los años veinte-cuarenta, es decir, desde la constitución del Partido Popular Italiano hasta los años de su exilio, para terminar con el nacimiento de las NEI en 1947, véase Niels Arbø1, I democristiani nel mondo, Milano, Edizioni Paoline, 1990, 62-63; y, acerca de los pasos de las organizaciones regionales DC para llegar a la creación de la UMDC en 1961, ibid., 64-68, y Papini, op. cit., 33-72.

72 Acerca de esta última reunión, véase el saludo enviado por el secretario político del partido Aldo Moro (miembro del comité de honor junto a Amintore Fanfani, en aquel entonces presidente del Consejo de Ministros) y un memorándum de preparación del Congreso, en Archivo Histórico del Istituto Luigi Sturzo (en adelante ALS), Fondo della Democrazia Cristiana, Segreteria Politica, caja 158, fascículo 13; la carta de Amintore Fanfani a Eduardo Frei, en la cual comunicaba la composición de la delegación italiana (CFF, Carta de Amintore Fanfani a Eduardo Frei Montalva, 10 de julio de 1951, Correspondencia Internacional, CC/2-2-IT) y Gazmuri, op cit., 523-524.

73 En efecto, la DC europea fue incapaz de "concebir y proyectar una política internacional que se saliera del marco del 'atlantismo' dependiente [...] No intentó recuperar un mínimo de autonomía con la cual habría podido poner en marcha la distensión y el desarme [...] Y ni siquiera se percató de las voces de protesta de los países del Tercer Mundo". Brèton, op. cit., 32 .

74 Karl Josef Hahn, "Le forze della Democrazia Cristiana fra Europa e Terzo Mondo", en Civitas XIV:4-5, Roma, abril de 1963, 3-15. El artículo de Hahn examinaba el estado de la cooperación entre los partidos democratacristianos europeos y aquellos de los demás continentes después de dos años del nacimiento de la UMDC, haciendo hincapié en lo que todavía hiciera falta hacer para mejorar la colaboración en el plano mundial. 
Probablemente Hahn había sido a su vez testigo de las quejas de los "amigos" democratacristianos extraeuropeos y, en particular, los latinoamericanos. No es casual que algunos meses antes, ad portas de la campaña electoral presidencial, Eduardo Frei Montalva le enviara una dura carta, en la cual denunciaba la publicación de un artículo, con el patrocinio del Centro Internacional de Estudios y Documentación, sobre la situación política de América Latina, en el cual, en la parte concerniente a Chile, según él, se habrían publicado noticias completamente "falsas", particularmente las referidas a las divisiones internas de la Democracia Cristiana chilena, al fuerte vínculo del partido con las jerarquías eclesiásticas nacionales y a la escasa afiliación entre los obreros ${ }^{75}$.

Sin embargo, no cabe duda de que la elección de la capital chilena como sede para el nacimiento de la UMDC representó un importante reconocimiento, sobre todo simbólico, a la Democracia Cristiana local, que apenas a cuatro años de su constitución ${ }^{76}$ ya había logrado imponerse como una de las formaciones políticas más prestigiosas en el panorama nacional y latinoamericano; y que tres años después logró que se escogiera como Presidente de la República a su candidato.

"La DC [chilena] llegó al poder con la mayoría absoluta y el eslogan 'revolución en libertad'. El camino recorrido fue lento y difícil. La DC actuó conjuntamente con los partidos marxistas en las elecciones, en el parlamento y en las organizaciones sindicales, a través de alianzas, acuerdos tácticos y gestiones comunes. La Falange nacional en un primer momento y la DC que la siguió después, establecieron su acción en la perspectiva de un cambio social profundo y de una ampliación de la vida democrática además del perfeccionamiento de las libertades políticas y sindicales. Surgido del viejo tronco conservador, el partido había ido precisando su orientación en la medida que se distinguía de las posiciones y de los intereses de la derecha que había terminado por ser el adversario político más inflexible y tenaz. Todo medio había sido usado para negar la legitimidad ideológica de la DC: desde desvergonzadas iniciativas hacia las altas jerarquías religiosas a una sistemática denigración de sus dirigentes y de sus actos"77.

$* * *$

Durante los años de gobierno de Frei Montalva, hubo una acentuación de los intercambios y de los contactos entre la DCI y el PDC, y una profundización de la dimensión "político-partidista". "El interés de la Democrazia Cristiana (DC) hacia Latinoamérica aumenta en esos años también gracias a la victoria electoral

75 Frei terminaba la misiva señalando, además, que "algunos dirigentes italianos nos han visitado, se han informado y han tratado de entender y ayudar. En cambio este folleto de ser repartido, nos hace un gran daño y por eso nuestra protesta". CFF, Eduardo Frei Montalva a Karl Josef Hahn, 12 diciembre de 1962, Italia 1945-1963, CC/2-3-IT.

76 Acontecida, como se sabe, en 1957, por la unión de la Falange Nacional y otros grupos socialcristianos. Sobre la Falange y el pasaje al PDC, léase de Alberto Sepúlveda Almarza, Los años de la patria joven: la política chilena entre 1938-1970, Santiago, Ediciones Chile América CESOC, 1996; y José Díaz Nieva, Chile: de la Falange Nacional a la Democracia Cristiana, Madrid, Universidad Nacional de Educación a Distancia, 2001.

77 Brèton, op. cit., 37. 
de la Democracia Cristiana chilena en 1964" y al logro de la presidencia de su líder más importante ${ }^{78}$.

Como ya he señalado, la DCI -o para ser más precisos, como veremos más adelante, algunos de sus exponentes- había seguido la evolución política chilena y, particularmente, la trayectoria de la Democracia Cristiana desde antes de la victoria de Frei. Por otro lado, entre este último y algunos de los más influyentes exponentes italianos ya existían, hace algunos años, relaciones estrechas, que fueron muy importantes durante el período de gobierno, tanto en lo que respecta a los lazos interpartidarios, como a nivel de relaciones bilaterales entre los Estados. Incluso antes de su llegada a la presidencia, Eduardo Frei había estado, de hecho, a menudo en Italia (y en Europa) tejiendo la red de contactos que habría utilizado largamente en los años siguientes para reunir fondos y apoyo para su carrera política, y para dirimir a su favor los contrastes internos del partido ${ }^{79}$.

Las relaciones con los amigos italianos fueron determinantes durante la campaña electoral para las presidenciales de 1964. Sereno Freato, en ese entonces secretario administrativo y fiel colaborador de Aldo Moro, se comprometió con un programa de ayuda financiera al PDC, llevado finalmente a cabo en el trienio de 1962 a 1964. Al parecer, la suya fue una iniciativa personal o, de todas maneras, circunscrita a pocas personas al interior del partido y que no involucró, inicialmente, a la Sección Exteriores ni a gran parte de los dirigentes ${ }^{80}$. Lo mismo es válido para lo que concierne a otra iniciativa, impulsada también por Freato, y dirigida asimismo a Latinoamérica.

Antes de detallar la ayuda ofrecida a la DC chilena, que aquí nos interesa, se señala de hecho de que en ese período Freato patrocinó también un programa de apoyo a todas las formaciones democratacristianas latinoamericanas, aunque menos consistente en términos financieros. La iniciativa le fue propuesta por Roberto Savio ${ }^{81}$, luego de que este último, en 1962, había realizado una larga gira por América Latina, durante la cual había compartido con exponentes de primer plano de la fuerzas democratacristianas locales (en Chile, en particular, con Eduardo Frei

78 Guarnieri y Stabili, op. cit., 229.

79 Acerca de los muchos viajes que Eduardo Frei realizó a Estados Unidos y Europa, desde 1959 hasta casi el día de las elecciones presidenciales, véase Gazmuri, op . cit., 525-547.

80 Esta es la opinión de Roberto Savio que, en una entrevista concedida al autor el 17 de abril de 2007, ha precisado reiteradas veces que las "operaciones chilenas" fueron por iniciativa personal de Sereno Freato y no de la DCI. Según él, solo después de la victoria de Frei, y con Mariano Rumor a la guía de la secretaría del Partido, se institucionalizó la relación con el PDC, siguiendo canales más formales y, en lo que atañe a los financiamientos, involucrando directamente la Sección Exterior del partido. La opinión de Savio acerca del rol de esta última contrasta, sin embargo, con lo que emerge de la documentación guardada en el Archivo de la Fundación Frei y, específicamente, la correspondencia de 1963 entre Frei y Angelo Bernassola, acerca de la cual hablaremos más adelante.

81 Roberto Savio empieza su carrera profesional como periodista. Posteriormente, entra al equipo de Moro, su referente al interior del partido, y se ubica en la Sezione Esteri de la dirección central de la DCI, dirigida en aquel entonces por Angelo Bernassola. A mediados de los años sesenta funda la Inter Press Service, agencia de prensa nacida sobre las cenizas de la Roman Press Service, que dirige por muchos años y de la cual es actualmente presidente honorario. En aquellos años trabaja además para muchas organizaciones internacionales y hasta el día de hoy desarrolla una intensa actividad como analista de política internacional. 
y Radomiro Tomic). Savio preparó un Plan mínimo de ayuda a los partidos DC de América Latina, por una suma total de 60.000 dólares al año ${ }^{82}$. Esto incluía la destinación de fondos para todas las formaciones democratacristianas latinoamericanas, exceptuando la venezolana y la chilena, desde el momento en que para estas dos fuerzas ya existían programas ad hoc, con financiamientos bastante más conspicuos y, sobre todo, porque sobre ellas se concentraban las rivalidades y las visiones opuestas de la DCI y de la Christlich Demokratische Union Deutschlands (CDU, Unión Cristiano-Democrática Alemana $)^{83}$.

El "plan mínimo" fue acogido favorablemente por Freato, y de común acuerdo con Peter Molt de la Fundación Konrad Adenauer y August Vanistendael, ya exponente de renombre de la Confederación Sindical Cristiana y desde 1952 secretario de la Confederación Internacional de los Sindicatos Cristianos, fue la base de una suerte de fondo solidario para los partidos democratacristianos, a través del cual se financió a los partidos católicos latinoamericanos, fondo carente de personalidad jurídica y que fue apartado luego de la victoria de Frei, cuando, como se señaló anteriormente, Mariano Rumor decidiera que había llegado el momento de institucionalizar las relaciones interpartidistas y, sobre todo, de concertar mejor las intervenciones con los pares europeos, en primer lugar Alemania, insertando la colaboración interoceánica en un marco dotado de mayor capacidad organizativa y de eficiencia, en vez de individualidades e iniciativas ocasionales.

Volviendo a Chile, y pensando en el apoyo que Freato garantizó especialmente a Eduardo Frei, es necesario destacar que en octubre de 1962, Franco Cortesi, joven y brillante exponente de la DC de Bergamo, fue enviado a Santiago en vista de las elecciones presidenciales chilenas, con la tarea "de ayudar a la DC chilena y especialmente a su líder Eduardo Frei Montalva, tanto con ayuda económica como con asesoría personal, a modo de manifestar el interés y la solidaridad que la DC italiana quería demostrar hacia su hermana chilena" 84 . Cortesi había sido contactado telefónicamente algunos meses antes por Filippo Pandolfi ${ }^{85}$-según sugerencia

82 Piano minimo di aiuti ai partiti DC dell'America Latina, s/a, elaborado por Roberto Savio, gentilmente concedido al autor de este ensayo. Una versión muy reducida del plan, entregada por Savio a Bernassola y titulada "Programa de ayudas a la Democracia Cristiana Latino Americana", se encuentra en ALS, Fondo della Democrazia Cristiana, Segreteria Politica, caja 159, fascículo 15. Para más detalles acerca de esta iniciativa, véase Rafaelle Nocera, "Dove non osò la diplomazia. Alcune riflessioni sull'internazionalismo democristiano e sulle relazioni italo-cilene, 1962-1970", en Ricerche di Storia Politica 1, Bologna, 2009.

83 Esencialmente, la CDU apoyó el COPEI venezolano, mientras que la DCI ayudó al PDC, en aquel entonces con vocación reformista y mucho más cercana, en relación a los democratacristianos venezolanos, a los lineamientos de centroizquierda de los colegas italianos. Hay que notar que, una vez llegado a la secretaría del partido, Mariano Rumor (con la ayuda de Angelo Bernassola) empezó a ocuparse en primera persona de los "asuntos latinoamericanos", determinando, de hecho, la salida del escenario de Sereno Freato. Rumor se esforzó -sin embargo, con modestos resultados- en superar las divisiones y las tensiones con la CDU, iniciando, de acuerdo con los alemanes y golpeando a la UMDC, una política uniforme para toda América Latina, que no tomó más en cuenta el criterio divisorio seguido hasta aquel entonces por italianos y alemanes.

84 Entrevista a Franco Cortesi, 30 de mayo de 2007.

85 Parlamentario democratacristiano, desde 1976 hasta 1988, fue posteriormente ministro de las Finanzas, de Economía y Hacienda, de Industria y de Agricultura. 
de Gian Battista Scaglia, en ese entonces vicesecretario nacional del partido- para saber si estaba interesado en experimentar en América Latina. Habiendo llegado a Roma, recibió instrucciones más detalladas directamente ${ }^{86}$ de Sereno Freato. Luego, partió hacia Chile, donde oficialmente se presentó como enviado de Il Popolo, aunque hubieran sido escasos los artículos publicados por el periódico de la DCI ${ }^{87}$ : "el carácter reservado de la iniciativa se confirma también por el hecho que ningún exponente de la DC italiana, exceptuando al director de Il Popolo, estaba al tanto de mi presencia en Chile. Tampoco lo estaba el Departamento de Exteriores de la DC, dirigido por el abogado Bernassola" 88 .

Pero, en realidad, además de facilitar el contacto político entre los dos partidos, sus tareas fueron diversas, y entre estas figuraba la de entregar personalmente a Eduardo Frei una suma mensual de 8.000 dólares $^{89}$-por un importe total, hasta las elecciones presidenciales, de casi 200.000 dólares $^{90}$, dinero que fue utilizado para el cumplimiento de las exigencias organizativas del PDC, para los gastos de la campaña para las elecciones administrativas de marzo de 1963 y para las presidenciales del año siguiente.

Con ocasión de la primera elección entre las anteriormente mencionadas, Cortesi envió un informe a Roma, en el cual, además de señalar el óptimo resultado de

86 Según Cortesi, el proyecto había nacido en ocasión de un anterior viaje de Freato a América Latina y pedía que "el acuerdo de colaboración -presencia en Santiago de un representante de la DC italiana y ayudas económicas en vista de las presidenciales del 64- fuese entre Frei y Freato". Idem.

87 En una carta reservada enviada el 25 de abril de 1963 a Scaglia y Freato, sobre la cual volveremos más adelante, Cortesi juzgaba la "fórmula del 'periodista' [...] inadecuada a su tarea, porque no permite la profundidad de contactos necesarios", quejándose además del hecho de que $I l$ Popolo no hubiese, hasta aquel entonces, publicado siquiera "una línea sobre Chile". Franco Cortesi, Carta reservada personal al honorable G. Battista Scaglia y al doctor Sereno Freato, 25 de abril de 1963, gentilmente concedida al autor. Dos artículos de Franco Cortesi fueron publicados, sin embargo, en la revista Política y Espíritu: "Los orígenes de la Democracia cristiana chilena" y "Un problema para el Occidente: la América Latina", Nº 282, agosto-septiembre de 1963, 28-29, y No 283, octubrediciembre de $1963,49-50$ y 80 , respectivamente.

88 Entrevista a Franco Cortesi, cit. Cortesi manifiesta además que, durante su estadía, tuvo "pocas relaciones con la colectividad italiana y ninguna con la Embajada". El "carácter reservado" al cual hace alusión Cortesi no tuvo que durar mucho, y sucesivamente Angelo Bernassola y, por lo tanto, la Sezione Esteri del partido fueron seguramente informados de su estadía y de las tareas que estaba desarrollando, aunque es probable que en ese entonces él no fuera informado. Es lo que se entiende por una comunicación del 17 de junio de 1963 de Angelo Bernassola a Eduardo Frei. CFF, Carta de Angelo Bernassola a Eduardo Frei Montalva 17 de junio de 1963, Correspondencia Internacional, CC/2-3-IT.

89 Cortesi afirma: "Mensualmente una carta personal de Freato me informaba del abono a mi nombre en un Banco (a menudo era el Banco Nacional de Trabajo). Me dirigía a la caja para el cobro y el cambio de dólares en pesos". Entrevista a Franco Cortesi, cit.

90 Savio afirma que la suma manejada por Cortesi fue solo una parte del financiamiento entregado por la DCI y que, por lo tanto, se trató en total de una suma más elevada, es decir, poco menos de 700.000 dólares, suma que Freato "encontró" y "tomó" presumiblemente "de los financiamientos al partido, procedentes del sector público (Ente Nazionale Idrocarburi -ENI-, Istituto per la Ricostruzione industriale -IRI-, etc.) y de muchos sectores privados". Entrevista a Roberto Savio, 17 de abril de 2007. Sea cual haya sido el importe exacto de la ayuda italiana, es peculiar constatar que los democratacristianos chilenos de primer plano en aquella época, o que se habrían convertidos en tales después de poco tiempo, sigan negando, hasta el día de hoy, la existencia de financiamientos italianos. Es lo que sostiene, solo por poner un ejemplo, el ex Presidente de la República Patricio Aylwin Azócar, en una entrevista concedida al autor en diciembre de 2005. 
los democratacristianos chilenos y las buenas oportunidades de victoria al año siguiente, destacaba:

"nuestra ayuda fue tempestiva y determinante en dar una base financiera segura, sobre la cual planificar un mínimo de organización y de actividad. El PDC lo necesitaba mucho, ya que se encontraba prácticamente paralizado en cada proyecto e iniciativa por falta de fondos. La campaña publicitaria fue la mejor que el partido hubiera hecho nunca, y a juicio de expertos, la mejor y la más eficiente en estas últimas elecciones. Algunos partidos llegaron a hacer insinuaciones e ilaciones sobre la 'millonaria' campaña del PDC, sobre todo los radicales y los comunistas" ${ }^{\text {91 }}$.

Más adelante, como conclusión a la extensa misiva, Cortesi sugería continuar apoyando a los democratacristianos chilenos en los meses siguientes (como de hecho ocurrió):

"Propongo que los 8.000 dólares mensuales sean destinados íntegramente al fortalecimiento del partido y de sus estructuras organizativas, a la realización del plan de penetración campesina, al fortalecimiento de la corriente sindical cristiana. Considero que los gastos para la campaña presidencial propiamente tal pueden ser abordados por Frei y por el partido sin intervenciones especiales de parte nuestra" ${ }^{92}$.

Sin embargo, para los meses venideros, Cortesi sugería "un sistema más seguro e indirecto para la entrega concreta de la ayuda, que el usado actualmente", la creación de una filial en Santiago de la Agencia Italia o de una filial del Instituto de Estudios y Documentación DC de Roma; de todas maneras, expresaba, "es indispensable una calificación técnica específica y una relación de representación evidente con la DC italiana o europea"93.

Sereno Freato respondió a Cortesi algunos meses después, luego de una visita de Frei a Roma (en el mes de mayo) ${ }^{94}$, invitándolo a prorrogar su estadía hasta las presidenciales 95 e informándole que "estamos estudiando las nuevas formas de pago. Por mientras a Frei le entregué una pequeña colaboración extra por nuestra parte" 96 . Pero, al parecer, a Frei el dinero no le era suficiente, o, al menos, las

91 Franco Cortesi, Carta reservada personal al honorable G. Battista Scaglia y al doctor Sereno Freato, cit.

92 Cortesi proponía además financiar, con “el otorgamiento de una suma (¿30.000 dólares?) 'una tantum", la creación de un diario de partido o, en alternativa, "de valorar la Radio Cruz del Sur" con un gasto de 60.000 dólares que, sin embargo, "sería anticipada a título de crédito". Idem.

93 Estas consideraciones eran formuladas como cierre de una petición muy explícita de interrumpir su estadía chilena o, por lo menos, reformularla sobre nuevas y diferentes bases, ya que "mi experiencia, que ha sido de tipo "exploratorio', no puede ser repetida de la misma manera" y "dadas las condiciones en las cuales me encuentro, tengo la impresión de haber terminado mi tarea". Idem.

94 Desde el 18 de abril, Frei desarrolló "un viaje de tres semanas por Estados Unidos, Italia y República Federal Alemana". En Italia sostuvo encuentros con el "Presidente de Italia, Antonio Segni; con el Primer ministro, Amintore Fanfani, y con el Secretario del Partido Demócrata Cristiano, Aldo Moro" (Gazmuri, op. cit., II, 541-542).

95 Después de su experiencia en Chile, Cortesi volvió a ocuparse de su profesión -asegurador- y de la política a nivel local en Bergamo.

96 Sereno Freato, Carta a Franco Cortesi, 5 de junio de 1963, gentilmente concedida por Cortesi al autor. 
promesas de los amigos italianos no lo reconfortaban del todo, considerando que volviendo a Santiago le escribió una carta a Roberto Savio, donde le solicitaba insistir ante Freato sobre la importancia de la ayuda prometida ${ }^{97}$, y luego directamente a la mano derecha de Moro, destacando

"la importancia que tendrá para nosotros la ayuda que Uds., tan generosamente me prometieron. Es algo vital. El señor Cortesi está escribiendo para indicarle la forma de proceder [...] estoy convencido que su intervención en todo esto la considero decisiva, pues sin esta ayuda suya en este momento estaríamos en una situación muy difícil"98.

Poco menos de dos meses después, Frei enviaba otra carta a Freato, en la cual, luego de haberlo actualizado sobre el inicio de la campaña electoral y de los progresos del PDC, le recordaba nuevamente que

"El problema central sigue siendo el de los gastos que son abrumadores [...] No quiero insistirle sobre esta materia porque sé su buena voluntad. Para mí esto es decisivo porque he tomado compromisos basado sobre lo que me dijera en Roma [...] Le ruego que no nos olvide y piense que estoy trabajando contando con su generosa ayuda" 99 .

Freato no retrocedió. En septiembre de ese año, Cortesi se ponía al día con satisfacción sobre los importantes avances realizados por los democratacristianos chilenos. Según él, con respecto a la campaña electoral de 1958 -a la que Frei se había presentado por primera vez como candidato presidencial- "existe hoy un partido de mayoría relativa que ha madurado notablemente; existe el apoyo de amplios sectores de la Iglesia; existe nuestra ayuda financiera; el mismo candidato está hoy tal vez más conciente de su colocación política, defendiendo los intereses auténticamente populares" 100 . Pero era necesario hacer más, sobre todo en términos monetarios, para alcanzar el éxito final. El joven democratacristiano de Bergamo apuntaba de hecho:

"El esfuerzo que debe realizar todo el partido para llegar al éxito es indudablemente grande, ya que es necesaria una constante y maciza presencia tanto en el plano organizacional como en el publicitario. Con este fin, debo decir que el aspecto financiero adquiere una importancia esencial. Sobre un presupuesto de gastos totales de 500.000 dollari, nuestra colaboración actual cubriría poco más de la quinta parte si continuara el mismo monto en el tiempo. No se contemplan otros aportes externos: los alemanes se

97 "La ayuda de Uds. será definitiva y decisiva. Freato es el hombre para tomar las decisiones y tengo mis esperanza en él [...] Le ruego insistir ante Freato sobre la importancia decisiva de su ayuda pues para nosotros es vital". $C F F$, Eduardo Frei a Roberto Savio, 26 de mayo de 1963, Italia 19451963, Italia 1945-1963, CC/2-3-IT.

98 CFF, Eduardo Frei a Sereno Freato, 28 de mayo de 1963, Italia 1945-1963, CC/2-3-IT.

99 CFF, Eduardo Frei a Sereno Freato, 18 de julio de 1963, Correspondencia Internacional, CC/ 2-3-IT.

100 Franco Cortesi, Carta reservada personal al honorable G. Battista Scaglia y al doctor Sereno Freato, 5 de septiembre de 1963, gentilmente concedida al autor. 
comprometieron con un aporte de 70.000 dollari, pero hasta ahora, no hay rastro de aquello"101.

Cortesi indicaba luego las modalidades de gasto de la financiación italiana, que merecen ser señaladas:

\begin{abstract}
"Hay que destacar que casi 5.000 dólares mensuales que vienen de nuestro aporte, son destinados exclusivamente para los gastos operacionales del partido (empleados de la sede central; 32 activistas sindicales; 25 activistas campesinos; empleados de las sedes periféricas de Valparaíso, Concepción, Cautín y del Sur). Los otros 3.000 dólares se destinan a la secretaría de la campaña, para gastos de arriendo de los locales, personal, giras del candidato a las provincias, etc. Por lo tanto, todo el sector de la propaganda y todos los gastos de carácter electoral propiamente tal (como la organización de congresos, reuniones, etc.) quedan a cargo de los auspiciadores locales del partido, quienes a pesar de ser numerosos y constantes, son débiles económicamente. Será necesario además en un futuro, emitir publicaciones diarias y por lo tanto, hacerse cargo de los consiguientes compromisos monetarios".
\end{abstract}

Es por esto que nuevamente hervía la idea "de continuar hasta fin de año, con el aporte mensual actual, más el aporte extraordinario de 15.000 dólares en Octubre para la Radio Cruz del Sur102, y luego, durante el '64 aumentar en 3-4.000 dólares los depósitos mensuales, para abordar las necesidades de los amigos chilenos".

En uno de sus últimos informes enviados desde Chile, con fecha 15 de abril de $1964^{103}$, Cortesi retomaba muchos de los temas tratados anteriormente, en primer lugar el del aspecto financiero, comunicando que "Frei requiere una ayuda inmediata de 70-100 mil dólares". Informaba, además, que la candidatura del líder democratacristiano ya era la que tenía mayores probabilidades de éxito y que su campaña electoral se estaba desarrollando sin mayores obstáculos, de hecho con mayor eficiencia en el plano organizacional, publicitario, y en el "sector de la prensa"104; que gracias a su intermediación, la FIAT de Santiago había puesto a disposición de Frei un automóvil "para sus giras electorales" (Cortesi suponía también que la empresa de Turín podría "haber puesto a disposición una decena de campagnole $e^{105 ") ; ~ y, ~ f i n a l m e n t e, ~ d e s t a c a b a ~ q u e ~ e r a ~ " m u y ~ i m p o r t a n t e ~ c r e a r ~ u n ~ c l i m a ~}$ de solidaridad externa a Frei", ya que "no cabe duda que la apuesta en las elecciones presidenciales chilenas es muy alta, no solo para ese país, sino para todo el mundo occidental".

101 Evidentemente, Cortesi no estaba en conocimiento de la ayuda norteamericana, acerca de la cual se hablará más adelante.

102 Casi al terminar la carta, Cortesi enfatizaba que con el mejoramiento ("gracias a nuestra ayuda") de esta emisora radiofónica, "la DC podrá disponer de un importante instrumento de presencia política no solo en Chile, sino que en otros países del continente donde la radio podrá ser escuchada". Idem. El financiamiento italiano fue por un total de 30.000 dólares.

103 Franco Cortesi, "Relazione, Cile (visita dal 15/3 al 8/4/64)", gentilmente concedida al autor.

104 A propósito de esto, señalaba "el apoyo que los diarios de la empresa editorial El Mercurio (la más importante de Chile) dan a la candidatura de Frei". Idem.

105 La campagnola es un automóvil todo terreno producido por la FIAT desde el 1951 hasta 1987. 
En este momento es válido preguntarse: ¿por qué Freato, tan cercano a Aldo Moro, invirtió tantos recursos y trabajo en la Democracia Cristiana chilena? Pareciera que Chile presentaba una suma de condiciones favorables, pero sobre todo una variedad de similitudes con la realidad italiana de ese período. Una explicación nos la brinda precisamente Franco Cortesi:

"La presencia de los partidos DC en América Latina, donde la única alternativa a los partidos conservadores o a las Juntas militares, parecía ser la revolución castrista de Cuba, podía representar el camino alternativo para las reformas y el desarrollo democrático. La situación de Chile parecía un buen entorno para el nuevo experimento. Pensando también en analogías particulares con la experiencia italiana: problemas de desarrollo económico y social similares a los que Italia atravesaba en ese período en la zona centro-sur, un líder DC como Eduardo Frei de gran estampa reformista que podía evocar a una figura como la de De Gasperi, un partido comunista chileno atento a las posiciones del partido comunista italiano y unido en el Frente Popular con un partido socialista formado por muchas almas, como en Italia. No es casual que en los comicios para la campaña presidencial, Frei habló del 'milagro económico' italiano realizado por la DC, prometiendo otro para Chile. En suma, la llegada a Chile, y por primera vez en América Latina de un presidente demócrata cristiano frente a conservadores y comunistas habría significado un éxito político internacional también para la DC de Moro. Un éxito político significativo también hacia los Estados Unidos, un aliado tan altamente interesado en el destino de Sudamérica, y además tan escéptico en las perspectivas de la política de centroizquierda ${ }^{106}$ dirigida por la DC italiana"107.

En el trienio entre 1962 y 1964, la DC italiana -o más precisamente, Freato y la corriente de Aldo Moro- se lanzó por lo tanto en un proyecto de ayuda financiera en un país de América Latina. Se trataba, claro, de cifras muy inferiores a las ofrecidas por el Departamento de Estado estadounidense ${ }^{108}$ y no se puede descartar que las sumas recogidas por Freato vinieran también, por no decir en gran parte, de Estados Unidos, en el sentido de que fueron apartadas de lo que la DCI recibía regular y copiosamente de Washington para "actividades varias". Muy probablemente el gobierno norteamericano estaba informado de esta inicia-

106 En aquellos años la historia italiana estuvo caracterizada por la experiencia política de centroizquierda, o sea, de la alianza de gobierno entre la DCI y el Partido Socialista (alianza hasta aquel entonces obstaculizada por Estados Unidos, preocupado de que el hecho pudiese constituir un peligro para la posición internacional de Italia). El primer gobierno de centro-izquierda, guiado por Aldo Moro, tuvo lugar en 1963, mientras que el último, después de sucesos varios, reunificaciones y quiebres al interior de la familia socialista, en el año 1976.

107 Entrevista a Franco Cortesi, cit. Savio afirma, por el contrario, que al financiar la DC chilena, Freato entreveía la posibilidad de "hacer negocios en América Latina", o sea que el reforzamiento de los lazos entre partidos pudiese favorecer una profundización de las relaciones económicas y de los intercambios comerciales. Entrevista a Roberto Savio, cit.

108 Como es sabido, en el año 1975, la comisión Church del Senado estadounidense estableció que se trataba de una suma entre los 3 y los 4 millones de dólares. El embajador norteamericano en Chile entre 1967 y 1971, Edward Korry, afirma, por el contrario, que las ayudas norteamericanas a la campaña electoral de Frei sumaron alrededor de 20 millones de dólares, recolectados por la Agency for International Development. Arturo Fontaine Talavera y Joaquín Fermandois, "El embajador Edward M. Korry en el CEP" [entrevista a Edward Korry], en Estudios Públicos 72, Santiago, primavera de 1998,75 y ss. 
tiva ${ }^{109}$, más aún, se puede suponer que la DCI actuó concertadamente con Estados Unidos, sobre la base de la consideración de que el partido italiano podía aprovechar las afinidades político-ideológicas con su contraparte chilena, en el marco de una imponente operación levantada por la administración Kennedy ${ }^{110}$. Edward Korry sostiene, de hecho, que la Casa Blanca se lanzó en un programa en grande, siguiendo el ejemplo de lo que había realizado Estados Unidos en Italia en 1948, con la finalidad de crear una "dinastía política demócrata cristiana" en el país andino, que gobernara por años y que fuera lo suficientemente estable y confiable como para recibir los aportes norteamericanos. Decía:

"En Santiago, organizaciones eclesiásticas nacionales y extranjeras coordinaron sus esfuerzos de recaudación de fondos en Europa con la CIA y la Casa Blanca; los montos reunidos por medio de esta operación conjunta, proveniente de organizaciones democratacristianas como la Adenauer Siftung de Alemania y de monarcas como el Rey de Bélgica, forman parte de las 'decenas de millones' [y representan] la cantidad recolectada por la administración Kennedy para financiar la operación realizada en Chile entre 1963 y 1964. El total podría considerarse como una suma alzada porque el Presidente decidió otorgar el completo respaldo del gobierno estadounidense a la campaña de Frei, porque la Casa Blanca coordinaba todos los gastos y porque los aportes provenientes del Viejo Mundo obedecían en su mayor parte a una decisión adoptada en la Oficina Oval"111.

Por lo tanto, a los dichos de Cortesi, hay que agregar otros más contextualizados del ex embajador Korry y suponer que la acción italiana entró en un proyecto más ambicioso planificado por la Casa Blanca, tendiente a favorecer el ascenso al poder en Chile de una fuerza política hacia la cual llevar los aportes previstos por la Alianza para el Progreso ${ }^{112}$ y, más generalmente, capaz de contrastar el "peligro comunista" y de asumir el rol de baluarte de la democracia.

109 En la entrevista citada en varias ocasiones, Cortesi recuerda un almuerzo de trabajo en Roma con Freato y Scaglia con la presencia de un funcionario de la embajada estadounidense en Italia, y sobre todo que, durante su estadía chilena, elaboró algunas relaciones acerca de la situación política del país latinoamericano, entregándolas exclusivamente a un "ciudadano norteamericano", cuyo nombre no recuerda, pero que "trabajaba en una compañía en el rubro del cobre". Savio afirma que Freato no había transmitido las informaciones a Estados Unidos.

110 Según Filippo Pandolfi, "no es la DC quien financia, la DC es el canal de financiamiento privilegiado de la CIA o de los servicios de intelligence del departamento de Estado", canal encargado de aprovechar el mecanismo de la solidaridad democratacristina internacional y las afinidades ideológicas. Entrevista a Filippo Pandolfi, 18 de julio de 2007.

111 Edward Korry, "Los Estados Unidos en Chile y Chile en los Estados Unidos. Una retrospectiva política y económica (1963-1975)", en Estudios Públicos 72, primavera de 1998, 65. Más adelante, en la ya citada entrevista a Fermandois y Fontaine, Korry alude también a "los contactos de la CIA y [padre Roger] Veckemans con los demócrata cristianos de Italia, para que estos enviaran ayuda a Chile. No se pude decir que fue una operación directa de Estados Unidos; pero si que cuando algo ocurría, finalmente era asumido por el contribuyente norteamericano, porque había que reembolsarle a Italia, quizás no todo, pero algo...”. Fontaine y Fermandois, op. cit., 79.

112 Por lo demás, precisamente la DC chilena fue considerada por Washington como la principal fuerza política, en el ámbito regional, capaz de realizar los propósitos previstos por la Alianza, mientras que su líder, Eduardo Frei, como el hombre político latinoamericano más en sintonía con la nueva estrategia norteamericana, volcada sustancialmente a evitar la difusión del comunismo en América Latina. Albert L. Michaels, “The Alliance for Progress and Chile's 'Revolution in Liberty', 19641970”, en Journal of Inter-American Studies and World Affairs 1, Miami, 1976, 74-99. 


\section{LAS RELACIONES INSTITUCIONALES}

Las maniobras mencionadas -fueran fruto de la iniciativa personal (de Freato), de una corriente de la DCI, o elaboradas de común acuerdo con Estados Unidos ${ }^{113}$, seguramente reservada, y sobre las cuales la diplomacia italiana en Chile no tenía conocimiento, desde el momento en que se utilizaron canales no oficiales- testimonian el gran interés y "solidaridad que la DC italiana quería demostrar hacia la hermana chilena" y, en general, la intención de proyectarse en un contexto geopolítico lejano y de obtener un éxito político internacional, para compartir con el aliado estadounidense. Tanto es así que la atención de Italia en esos años no estaba dirigida solo a Chile, sino a todo el subcontinente.

De hecho, en la primera mitad de los años 60, la diplomacia italiana se mostró más práctica y desenvuelta con respecto al pasado, orientada a verificar la factibilidad de una acentuación de la presencia de Italia en la región. En esta óptica se inserta el segundo viaje del presidente Gronchi a América Latina ${ }^{114}$, del 7 al 19 de abril de 1961, a Perú, Argentina y Uruguay, con una brevísima detención en Brasil ${ }^{115}$. Además de confirmar el interés "concreto con el cual Italia hace tiempo sigue la evolución de los países de América Latina”, profundizar la colaboración política y comercial con las tres naciones latinoamericanas visitadas y encontrarse con las colectividades italianas, el viaje tuvo, al parecer, también el implícito objetivo de proponer a Italia como una alternativa, aunque de menor perfil y consistencia, a Estados Unidos, aprovechando el amplio descontento hacia Washington; o por lo menos de presentar al gobierno italiano como un intermediario en las relaciones con la Casa Blanca y actor encargado de limitar su arrogancia y agresividad ${ }^{116}$.

No cabe duda de que la visita más importante fue la hecha a Argentina, país donde además Gronchi se detuvo por más tiempo (del 10 al 17 de abril), que llevó a que la declaración de Buenos Aires fuera la más significativa ${ }^{117}$. De hecho, hay

113 Posteriormente, durante la gestión de Rumor, no faltarían malentendidos con Washington, como se aprecia en una nota reservada enviada por Francesco Cossiga -en aquel entonces joven y brillante diputado democratacristiano, sucesivamente ministro del Interior, presidente del Consejo de Ministros y del Senado, y, entre 1985 y 1992, Presidente de la República- a Mariano Rumor, el 12 de agosto de 1965. Informándolo de los preparativos para su inminente viaje a Washington (programado para el 25 del mismo mes) y, en especial modo, de las charlas sostenidas con el jefe de la sección política de la embajada estadounidense en Roma, Peters, y con su asistente para los asuntos de la DC y de la Santa Sede, Cooke, Cossiga señalaba: "reactivaron la influencia de la DC en América Latina, a la cual, evidentemente empiezan a dar la importancia que corresponde". ALS, Carta reservada de Francesco Cossiga a Mariano Rumor, 12 de agosto de 1965, Fondo della Democrazia Cristiana, Segreteria Politica, caja 182, fascículo 2.

114 Giovanni Gronchi había viajado a Brasil en septiembre de 1958. Fue la primera visita de un jefe de Estado italiano a América Latina. F.R., "Il viaggio in Brasile del presidente Gronchi", en Relazioni Internazionali 38, Milano, 20 de septiembre de 1958, 1.071.

115 Esto seguía a las visitas oficiales realizadas el año anterior a la península, por los presidentes de Perú Manuel Prado (febrero), de Argentina Arturo Frondizi (junio) y de Uruguay Benito Nardone (noviembre).

116 B.C., "Il secondo viaggio latino-americano di Gronchi", en Relazioni Internazionali 14, 8 abril de $1961,403$.

117 Para un informe, véanse "I colloqui di Gronchi in Argentina", "Il benvenuto del presidente Frondizi", "La risposta di Gronchi" y, sobre el discurso del 12 de abril del jefe de Estado italiano 
que considerar todo el viaje como una etapa fundamental de las relaciones ítalolatinoamericanas de los primeros dos decenios de la segunda posguerra, como una confirmación del nivel de vivacidad alcanzado por Italia en América Latina, y como revelador del intento de la diplomacia italiana de proponerse como mediador entre Europa y el subcontinente ${ }^{118}$. En resumen, el objetivo ni siquiera tan oculto de Italia era el de estimular a los aliados europeos a profundizar las relaciones con los países latinoamericanos y el de autoatribuirse un rol de guía al interior de la CEE. Este objetivo no parece haber sido alcanzado, no tanto y no solo por eventuales incertidumbres por parte de Roma o por la resistencia de Estados Unidos, sino más bien por la indiferencia de los socios europeos. Estos, de hecho, no se mostraron muy interesados ni disponibles para acoger las invitaciones italianas a profundizar las relaciones con América Latina. En los años sesenta, el ministro de Relaciones Exteriores italiano Amintore Fanfani realizó infructuosos intentos en ese sentido $^{119}$. El 29 de junio de 1965, en la reunión de la Unione dell'Europa Occidentale (UEO) en Luxemburgo, Fanfani resaltó la importancia y (la problemática) de las relaciones con el subcontinente. Destacando la urgencia de una reflexión común entre todos los Estados miembros de la UEO, luego de la crisis cubana de 1962 y "la 'acción de los Estados Unidos en Santo Domingo"”, desde fines de abril de ese año, el Ministro propició una intensificación de las relaciones económicas entre la comunidad europea, la EFTA y los países latinoamericanos ${ }^{120}$. Sin embargo, por explícita decisión suya, esto debía ocurrir en el respeto de los intereses estadounidenses.

"La presencia política, económica y cultural de Europa en América Latina debe ser un elemento equilibrador y no debe considerarse como competidora de la presencia de los Estados Unidos. Ninguna acción nuestra debe, ni podría, renegar nuestra amistad y alianza con los Estados Unidos de América. La presencia europea en América Latina,

frente al parlamento argentino reunido en sesión extraordinaria, "Il presidente italiano esalta l'amicizia tra i due popoli", todos en Relazioni Internazionali 16, 22 de abril de 1961, 478-481. Para un balance de todo el tour, véase en cambio B.C., "Bilancio del viaggio latino-americano di Gronchi”, en Relazioni Internazionali 17, 29 de abril de 1961, 505-506.

118 Para Ludovico Incisa di Camerana, el bienio 1960-1961 y la segunda visita de Gronchi en particular testimonian "la adhesión italiana a la tesis desarrollista che preconiza [...] la industrialización acelerada [pero que] representa sin embargo un neto distanciamiento con respecto a la teoría monetaria sostenida en Washington por el Fondo monetario [...] Al alejamiento del plan de estrategia económico con el de la línea norteamericana se agrega una diferente visión de la relación entre Occidente y América Latina, cuyo núcleo ya no está enfocado en la cooperación entre Estados Unidos y América Latina, sino que en la cooperación entre América Latina y Europa Occidental [...] En resumen, se propone a América Latina, el modelo de desarrollo europeo y también una vía europea, la de la integración, para solucionar los problemas regionales". Ludovico Incisa di Camerana, "Italia e América Latina: dallo strabismo all'attenzione", en Relazioni Internazionali, octubre de 1995, 58.

119 De todas maneras el incremento de las relaciones entre Italia y América Latina llevó, a principios de la década, bajo propuesta italiana, a la constitución de una Subcomisión para el estudio de las relaciones entre CEE y América Latina. Ludovico Incisa di Camerana, "Il risveglio della democrazia in America Latina", en Ennio Di Nolfo (ed.), La politica estera italiana negli anni Ottanta, Manduria, Piero Lacaita Editore, 2003, 157.

120 "Coordinata collaborazione auspicata dall'On. Fanfani all'UEO", en Relazioni Internazionali 28, 10 de julio de $1965,674-675$. 
debe conservar la característica originaria e independencia, que la vuelve atractiva a los países de América Latina, y pueden darle autoridad para defender objetivamente ante estos todo lo positivo y constructivo que Estados Unidos desarrolla en el continente americano" $" 121$.

Estos conceptos inspiraron también el viaje que el Presidente de la República, Giuseppe Saragat, acompañado por Fanfani, cumplió entre el 10 y el 21 de septiembre de 1965 a algunos países latinoamericanos (Brasil, Uruguay, Argentina, Chile $^{122}$, Venezuela y Perú). La tercera visita de un jefe de Estado italiano a la región se anunció como una iniciativa italiana para relanzar su política hacia América Latina ${ }^{123}$. La "reconsideración de los problemas" de las realidades del subcontinente, como se dijo en ese momento, había sido predicha por Fanfani algunos días antes del viaje con Saragat, el 4 de septiembre, en ocasión de un almuerzo ofrecido a los embajadores latinoamericanos en Villa Madama. En aquella ocasión, el ministro de Relaciones Exteriores había anunciado la creación de un instituto ítalo-latinoamericano para la cooperación cultural y económica y para las relaciones humanas ${ }^{124}$. Lo expuesto e imaginado por Fanfani era un objetivo muy ambicioso, que se realizó solo en parte. A pesar de esto, se trataba de una propuesta original y muy esforzada que ponía a Italia en primera fila entre los países europeos, en la cooperación con el área latinoamericana. El gobierno italiano, por tanto, se transformaba en promotor de la creación de un organismo de enlace con todos los Estados de la región, con personalidad jurídica y de derecho internacional -el Istituto Italo-Latinoamericano (IILA)-, que nacería oficialmente luego de intensas actividades diplomáticas entre Italia y las 20 repúblicas del hemisferio americano, en Roma el 1 de junio de $1966^{125}$, "con el voto favorable en el Parlamento de la oposición comunista"126.

El anuncio de Fanfani sobre la IILA ocurrió exactamente un año después de las elecciones presidenciales chilenas y la victoria de Frei, que recibió gran cobertura mediática en Italia ${ }^{127}$, con numerosos recortes y artículos publicados en

121 Ibid., 675

122 En Santiago, Fanfani, además de los encuentros oficiales, tuvo uno el 19 de septiembre con la dirección nacional del PDC. Para un informe y el discurso pronunciado por el ministro de Relaciones Exteriores italiano, véase Boletín PDC 4, Santiago, septiembre de 1965, 9-13.

123 B.C., "Il presidente Saragat nell'America Latina", en Relazioni Internazionali 37, 11 de septiembre de 1965, 851-852.

124 "Fanfani propone un istituto di cooperazione culturale ed economica", en Relazioni Internazionali 37, 11 de septiembre de 1965, 863.

125 Luigi Vittorio Ferraris (ed.), Manuale della politica estera italiana 1947-1993, Roma-Bari, Laterza, 1996, 206.

126 Guarnieri y Stabili, op. cit., 229. Para el texto de la convención Relazioni Internazionali 26, 25 de junio de 1966, 696-697. Véase también Instituto Ítalo-Latino Americano, Decimo anniversario, Roma, IILA, 1976.

127 El embajador chileno en Italia, Hernán Cuevas Y., había entregado una inmediata comunicación en un despacho del 7 de septiembre, en el cual enfatizaba "la extraordinaria repercusión en Italia" de la vuelta electoral, considerando sobre todo el hecho de que "comúnmente la prensa italiana, no entrega las noticias sobre lo que sucede en los países latinoamericanos". Archivo del Ministerio de Relaciones Exteriores (en adelante AMRE), Embajada chilena en Roma a Ministerio de Relaciones Exteriores, Oficio Ordinario n. 559/138, 7 de septiembre de 1964, vol. 157. 
los principales periódicos, notas radio-televisivas y comentarios como el aparecido en la revista de la ISPI Relazioni Internazionali, la cual, en el número del 12 de septiembre de $1964^{128}$, ensalzaba precisamente el resultado obtenido por Frei, destacando el éxito "neto" e "inesperado"129. Una semana después, era el turno de un breve pero elogiador retrato de Eduardo Frei, político "indudablemente dotado" y "primer presidente demócrata cristiano de una República de América Latina"130.

Los artículos publicados en ocasión de la victoria de Frei brindaron una primera y parcial representación de lo que había sucedido y hasta ahora sucedía en Chile, pero obviamente no colmaron la esencial indiferencia mostrada por los medios de comunicación hasta ese entonces. En 1964, por lo tanto, se sabía todavía muy poco en Italia de la Democracia Cristiana chilena. Pero la curiosidad y el interés por el PDC y por la política chilena en general no demoraron en crecer y, en ese sentido, la victoria de Frei fue un acelerador. Uno de los primeros intentos por informar a la opinión pública italiana ${ }^{131}$ y por ofrecer una primera comprensión sobre las formaciones democratacristianas latinoamericanas y chilena fue el artículo de José Luis Gotor, en el que se examinaban los principios inspiradores y algunos aspectos de la ideología democratacristiana del subcontinente, además de los pasos más importantes cumplidos por los partidos DC, a través de los escritos de algunos de sus principales exponentes. Por el lado de las "funciones", Gotor señalaba:

“Algunos observadores políticos atribuyen a la Democracia Cristiana latinoamericana la misma función de freno anticomunista que la Democracia Cristiana tuvo en Europa en la posguerra inmediata. Esto puede también ser posible, pero lo que es importante destacar es que hoy los católicos [...] tienden a constituirse como partido de masa, a crear, sobre la base de la doctrina social de la iglesia [...] una tercera posición de revolución 'integral', que se posiciona como alternativa al comunismo y al capitalismo, y al gobierno con el liberalismo, el radicalismo de izquierda y el conservacionismo [...] La función inmediata y urgente que los partidos demócrata cristianos proponen poner en práctica es la de integrar políticamente a las masas rurales, modernizar las estructuras de una sociedad arcaica, promoviendo drásticas reformas agrarias, tributarias y educacionales, asegurándose al mismo tiempo la aprobación de los estratos medios"132.

128 F.R., "La vittoria di Eduardo Frei", en Relazioni Internazionali 37, 12 de septiembre de 1964, 1179-1180.

129 La revista ya se había ocupado de las elecciones chilenas cuatro meses antes de la votación, en L.G., "Prospettive nuove per le elezioni cilene" ( $\mathrm{N}^{\mathrm{o}}$ 18, 2 de mayo de 1964, 672-673).

130 "Eduardo Frei", en Relazioni Internazionali 38, 19 de septiembre de 1964, 1209. Hay que notar que en la ceremonia de asunción del mandato presidencial, la misión extraordinaria italiana estaba conformada por Gian Battista Scaglia (jefe de la misión), Luigi Valdettaro della Rocchetta (consejero diplomático del Presidente de la República), Sereno Freato y Roberto Savio.

131 Mas no el primero. Véase, solo como ejemplo, el número de la revista mensual Il Nuovo Osservatore, de enero de 1964, con varios artículos sobre América Latina y sobre las DC del subcontinente, con aportes de democratacristianos italianos y latinoamericanos, entra los cuales se encuentra el de Eduardo Frei, titulado "La rivoluzione nella libertà".

132 José Luis Gotor, "La Democrazia Cristiana nell'America Latina”, en Il Mulino 9, Bologna, septiembre de $1964,897$. 
En las proyecciones, nadie comprometía completamente su posición, aunque se reconocían las grandes potencialidades de las formaciones democratacristianas latinoamericanas y los intentos por profundizar la colaboración internacional.

\begin{abstract}
"No sabemos cuáles serán las posibilidades reales de este movimiento, de este repunte de la Democracia Cristiana. Es cierto que trabaja hoy para organizar sus esfuerzos en un plano continental. Por otro lado, también la Democracia Cristiana europea (Alemania e Italia) [...] está intentando intensificar su acción en América Latina, colaborando con la formación de cuadros dirigentes, y promoviendo intercambios de estudio y de información y organizando seminarios" $" 133$.
\end{abstract}

La prudencia de Gotor se explicaba por el hecho de que la acción de gobierno de la DC chilena no había comenzado aún y, además, en esas semanas nacían fuertes temores sobre la posición de minoría parlamentaria del Ejecutivo al mando de la Democracia Cristiana, temores que se apartaron al año siguiente, cuando se saludaba con gran satisfacción el triunfo del PDC en las elecciones parlamentarias del mes de marzo y la conquista de la mayoría absoluta ${ }^{134}$. Todo parecía listo para aclamar también en Italia al líder más innovador de América Latina y para tributar el merecido homenaje a Chile y a la Democracia Cristiana chilena. Es dentro de esta óptica que debe enmarcarse el viaje de Eduardo Frei a Italia, del 2 al 4 de julio de $1965^{135}$, con ocasión de un tour europeo que lo llevó también a Francia, Gran Bretaña y Alemania ${ }^{136}$.

Antes de examinar más detalladamente la visita de Frei y los ulteriores desarrollos, es oportuno destacar que, a partir de entonces, si no incluso desde su victoria en las elecciones presidenciales, se presencia un especial cambio de registro, en el sentido de que desde una relación exclusivamente interpartidista se pasa a una relación principalmente institucional. Eso no significa que la colaboración (y el apoyo italiano) entre los dos partidos se detuviera, sino que sencillamente esta representó un factor adicional, que facilitó la cooperación diplomática y económico-comercial. En resumen, no cabe duda de que la mejoría cualitativa y cuantitativa de las relaciones ítalo-chilenas que se registró en el período entre 1965 y 1970 fue facilitada por el hecho de que fueron los políticos del mismo color los que dialogaron, pero no es menos cierto que a partir del ascenso al poder de Frei, ya no fue tema de discusión el tipo de ayuda que la DCI podía ofrecer a su contraparte chilena, sino cuáles caminos

133 Ibid., 900

134 "Trionfo della DC nel Cile", en Relazioni Internazionali 11, 13 de marzo de 1965, 252.

135 “Un viaje histórico", "El diario 'Il Giorno' de Milán entrevista al presidente Eduardo Frei” y "Comunicado oficial de la visita del presidente Eduardo Frei", en Política y Espíritu 290, mayo-junio de 1965, 11-14; y 291, julio-agosto de 1965, 30-36 y 38-39, respectivamente; pero véase además, solo como ejemplo, el comentario del embajador chileno en Roma Francisco A. Pinto, del 12 de julio de 1965, según el cual, a propósito de la cobertura mediática, "los artículos y las crónicas de los diarios y revistas, dedicadas a la visita, superaron los 1300". AMRE, Embajada chilena en Roma a Ministerio de Relaciones Exteriores, Aerograma n. 762/110, 12 de julio de 1965, caja 65.

136 Un informe puntual del viaje de Frei a Europa (y a América Latina) se encuentra en la circular enviada el 20 de noviembre de 1965 por el ministro de Relaciones Exteriores Gabriel Valdés Subercaseaux a todas las sedes diplomáticas en el exterior. AMRE, Circular Estrictamente Confidencial N ${ }^{\circ} 14$. 
seguir para fortalecer los lazos entre los dos países, quizás acercándolos lo más posible a los existentes entre Italia y sus socios históricos del subcontinente ${ }^{137}$.

Volviendo a la visita ${ }^{138}$, esta sirvió claramente también para tratar de mejorar los intercambios comerciales (tanto más cuando "Chile no es para Italia un mercado de grandes proporciones") ${ }^{139}$, pero más aún los vínculos interpartidarios ${ }^{140}$ -también en el marco del $\mathrm{UMDC}^{141}$ - y en forma más amplia, para relanzar sobre bases más sólidas las relaciones bilaterales. En esa ocasión, de hecho, y luego con la ya mencionada visita de Saragat a Chile, los dos gobiernos entablaron negocios en diversos ámbitos, poniéndose de acuerdo principalmente en la instauración de una Comisión mixta interministerial permanente encargada de favorecer la cooperación bilateral, la apertura por parte del gobierno italiano de una línea de crédito a Chile, para el desarrollo industrial y la ampliación de la asistencia técnica y la instalación en el país andino de industrias italianas (especialmente la FIAT). Los acuerdos logrados entre julio y septiembre de 1965 fueron perfeccionados al año siguiente. Con respecto a la línea de crédito, los dos gobiernos firmaban, el 1 de febrero de 1966, un acuerdo en base al cual Italia concedía un préstamo de 6 millardos 250 millones de liras a Chile, para la compra de maquinaria industrial italiana: las entidades encargadas de gestionar operativamente el préstamo fueron el Banco Central de Chile y el Istituto Mobiliare Italiano ${ }^{142}$.

137 El mejoramiento de las relaciones ítalo-chilenas se insertó en una estrategia de gran dinamismo de la política exterior del gobierno de Frei, centrada sobre todo en el refuerzo de la integración latinoamericana y, después del 1967, en una mayor autonomía con respecto a Estados Unidos. Joaquín Fermandois, Mundo y fin de mundo. Chile en la política mundial 1900-2004, Santiago, Universidad Católica de Chile, 2005, 302-324; Hofmeister, op . cit., 97-102.

138 Como confirmación de la sintonía existente entre las dos naciones, la de Frei fue precedida y seguida en el mismo año por muchas otras visitas de personalidades chilenas de primer plano, como, solo para citar dos, la del cardenal Raúl Silva Henríquez y la del presidente del Senado Tomás Reyes Vicuña, además de la de dos delegaciones parlamentarias. AMRE, Embajada chilena en Roma a Ministerio de Relaciones Exteriores, Oficio Confidencial No 265/12, 30 de abril de 1966.

139 B.C., "La visita del presidente Frei", en Relazioni Internazionali 28, 10 de julio de 1965, 659. Los temas comerciales fueron enfrentados también en el comunicado conjunto y en el discurso de Frei en el Campidoglio. Véase, en el mismo número de la revista, "L'operante solidarietà sottolineata dal comunicato finale" y "Frei invita l'Italia e 1'Europa a collaborare con 1'America Latina", 672 y 673674, respectivamente. Véase, además, el discurso pronunciado por Aldo Moro en honor al huésped chileno, durante un desayuno en Villa Madama ("Esaltati da Moro i comuni obiettivi", 672-673). Un acucioso análisis de los intercambios comerciales ítalo-chilenos se encuentra en AMRE, Embajada chilena en Roma a Ministerio de Relaciones Exteriores, Oficio Ordinario $N^{\circ}$ 298/75, 12 de mayo de 1966, con el cual se señalaba, entre otras cosas, que con respecto al año anterior, las exportaciones chilenas habían disminuido en un $0,2 \%$, y las italianas en un $8,2 \%$.

140 "La afinidad ideológica entre la formación política de Frei y la Democracia Cristiana italiana es un elemento que tiene su peso en la evaluación del viaje a Roma del Presidente chileno". B.C., "La visita del presidente Frei", op. cit., 659.

141 No es casual que en el "congreso de las DC europeas, que tuvo lugar en Taormina en el mes de diciembre de 1965 , el presidente Rumor afirmara que 'es nuestro deber entregar a los amigos latinoamericanos el apoyo más cálido, confiado y correcto. Es nuestro deber poner a disposición de su experiencia, nuestra experiencia cultural y política'”. Corghi, op. cit., 279.

142 Véanse AMRE, Embajada chilena en Roma a Ministerio de Relaciones Exteriores, Oficios Confidenciales $\mathrm{N}^{\circ} 81 / 6$ y $\mathrm{N}^{\circ} 265 / 12$, del 4 de febrero y del 30 de abril de 1966, respectivamente. En noviembre de 1967, con intercambio de notas, los dos gobiernos procedían a ampliar la línea de crédito de otros 3.125 millones de liras. AMRE, Nota enviada por el Ministerio de Relaciones Exteriores chileno a la Embajada italiana en Santiago, 6 de noviembre de 1967, caja "Italia, misión residente, 1967". 
El considerable estado de las relaciones bilaterales fue confirmado por la visita oficial a Chile del ministro de Economía y Hacienda Emilio Colombo, entre el 21 y el 23 de abril. Aunque su viaje fue principalmente de tipo "explorativo" "143, Colombo tuvo encuentros de alto nivel con el presidente Frei ${ }^{144}$ y los ministros de Relaciones Exteriores (Valdés), de Economía (Santamaría), de Hacienda (Molina) y de Agricultura (Trivelli), y con el presidente del PDC (Aylwin), durante los cuales se discutió la forma de profundizar las relaciones industriales y comerciales ${ }^{145} \mathrm{y}$, especialmente, un acuerdo entre empresas italianas y chilenas para la producción de manufactura de cobre y la instalación en Chile de la FIAT como socia de CORFO, para la producción de partes eléctricas de automóviles con licencia de la Marelli ${ }^{146}$.

Por razones de espacio no es posible alargarse en la evolución de la cooperación económico-comercial en los años siguientes. Basta destacar que los dos gobiernos trabajaron intensamente para potenciarla hasta fines del mandato de Frei, en 1970, y que de hecho, contrariamente a lo señalado por el embajador chileno Francisco A. Pinto en 1966, la situación mejoró sensiblemente, y entre 1965 y 1970 las compras italianas de productos chilenos experimentaron un crecimiento significativo,

“doblando, en 1970, la participación alcanzada en 1965. En este último año, las exportaciones de Chile a Italia representaban el 3,6\% de las exportaciones totales, mientras que en 1970 se elevaron hasta el 7,4\%. En este período, y específicamente en 1967, Italia tuvo su máxima participación en las exportaciones chilenas, con el 8,16\% del valor total, nivel que no fue posible alcanzar nuevamente en los últimos 20 años. Con respecto a las importaciones, se mantuvieron estables -alrededor del $2 \%$ - en el período" 147 .

Vale la pena señalar, además, que el mejoramiento de la cooperación fue posible sobre todo gracias a las numerosas misiones gubernamentales italianas y chilenas que llegaron a uno y otro país ${ }^{148}$. En todas las ocasiones en que las delegacio-

143 AMRE, Ministerio de Relaciones Exteriores a Embajada chilena en Roma, Oficio Confidencial $\mathrm{N}^{\mathrm{o}} 8,1$ de junio de 1966 .

144 En una carta enviada a Amintore Fanfani al mes siguiente, Frei hizo mención a la visita de Colombo, subrayando que su presencia confirmaba "una vez más la extraordinaria amistad que nos une con Italia y el hecho de que son Uds. los únicos en Europa que realmente comprenden el proceso político que estamos desarrollando". CFF, Eduardo Frei Montalva a Amintore Fanfani, 27 de mayo de 1966, Correspondencia Internacional, CC/2-2-IT.

145 "Colombo conclude la visita in Cile", en Il Popolo, Roma, 23 de abril 1966.

146 AMRE, Embajada chilena en Roma a Ministerio de Relaciones Exteriores, Oficio Ordinario $N^{\circ}$ 255/64, 26 abril de 1966; y Ministerio de Relaciones Exteriores a Embajada chilena en Roma, Oficio Ordinario, 29 de abril de 1966.

147 Instituto para la Cooperación Económica Internacional y los Problemas de Desarrollo (ICEPS), Venti anni di economia cilena. Analisi delle relazioni economiche e commerciali tra Cile e Italia e prospettive di cooperazione, Roma, ICEPS, 1987, 24.

148 Obviamente, no faltaron los encuentros entre representantes de los dos partidos - por lo tanto insertos en el marco interpartidista y no en el marco institucional- sobre todo en Italia. En este sentido, es necesario recordar la larga estadía de Patricio Aylwin en 1967, quien tuvo la ocasión de visitar prácticamente toda la península y de encontrarse con los dirigentes de la DCI y del gobierno italiano (en especial modo Fanfani, Moro, Rumor, Colombo). Cfr. las cartas enviadas desde Roma por Patricio Aylwin a Tomás Reyes Vicuña y al presidente Eduardo Frei, el 24 de abril y el 29 de septiembre de 1967, respectivamente (en custodia pero no catalogadas, en el archivo de la Corporación Justicia y Democracia). 
nes de los dos Estados se encontraron, en Roma o en Santiago, el denominador común fue precisamente el aumento de la colaboración bilateral en los ámbitos más variados, industrial, comercial, cultural, militar y obviamente político-diplomático. En este marco es necesario instalar, por tanto, a la misión económica y comercial italiana que llegó a Santiago entre el 11 y el 17 de abril de 1969, presidida por el parlamentario italiano Giuseppe Gerbino ${ }^{149}$, y la visita también a Chile, a fines de ese mes, del grupo de trabajo de los institutos ICEPS y SVIRES (Sviluppo Relazioni Estere) [Desarrollo de las Relaciones Exteriores] encargados de verificar la factibilidad de un programa de colaboración industrial, técnico, económico y financiero entre Italia y Chile ${ }^{150}$; la delegación comercial chilena de visita en Italia en septiembre de 1969151; la visita oficial a Roma del ministro de Relaciones Exteriores Gabriel Valdés, el 23 y 24 de octubre del mismo año ${ }^{152}$; la misión a Chile del presidente del IRI, Giuseppe Petrilli, entre el 18 y el 23 de abril de $1970^{153}$.

Los encuentros anteriormente mencionados testifican el significativo mejoramiento logrado en la segunda mitad de los años sesenta, en la senda de la mejoría cualitativa y cuantitativa de las relaciones bilaterales Italia-Chile y, aunque se manifieste solapadamente, de la profundización de los vínculos interpartidistas. A pesar de esto, a fines del decenio, al interior de la DCI, aún eran pocos los que estaban al tanto de lo que estaba sucediendo en Chile o los que sabían de los resultados de la Democracia Cristiana chilena y, más ampliamente, latinoamericana. Fue probablemente para responder a una exigencia de mayor conocimiento que en 1968 Angelo Bernassola publicó un libro que, como admitió en la breve introducción, se presentaba como un "modesto esfuerzo [...] cumplido especialmente para responder -sin pretender hacerlo completamente- a la exigencia de los que al interior y exterior de la DC, lamentan la fragmentación de las noticias concernientes al camino y a la incidencias de las ideas demócrata cristianas fuera de nuestro país" 154 . Con respecto al significado de la "revolución en libertad" de Frei, Bernassola escribía:

149 AMRE, Ministerio de Relaciones Exteriores a Embajada chilena en Roma, Oficio Ordinario, $\mathrm{N}^{\circ}$ 9563, 12 de mayo de 1969.

150 AMRE, Embajada chilena en Roma a Ministerio de Relaciones Exteriores, Oficio Confidencial $\mathrm{N}^{\circ}$ 129/18, 10 de marzo de 1969, pero véanse además las noticias publicadas en "Programma di cooperazione economica italo-cilena", en Il Globo, Roma, 6 de marzo de 1969; "L'Italia collaborerà allo sviluppo del Cile", en Il Messaggero, Roma, 6 de marzo de 1969; y "Accordo di cooperazione fra l'Italia e il Cile", en Il Tempo, Roma, 6 de marzo de 1969.

151 AMRE, Ministerio de Relaciones Exteriores a Embajada chilena en Roma, Oficio Ordinario $\mathrm{N}^{\mathrm{o}} 17593,12$ de septiembre de 1969.

152 AMRE, Embajada chilena en Roma a Ministerio de Relaciones Exteriores, Oficio Confidencial $\mathrm{N}^{\mathrm{o}}$ 606/64, 6 de noviembre de 1969 .

153 AMRE, Ministerio de Relaciones Exteriores a Embajada chilena en Roma, Oficio Confidencial $\mathrm{N}^{\mathrm{o}} 13,15$ de mayo de 1970 .

154 Angelo Bernassola, Democrazia Cristiana realtà internazionale, Roma, Edizioni Cinque Lune, 1968. En ese mismo año se lanzó para el mercado latinoamericano el libro de Paolo Emilio Taviani, Principios cristianos y método democrático, Firenze, Le Monnier, 1968 (publicado en Italia el año anterior), que contenía una recolección de ensayos aparecidos en su mayoría entre 1950 y 1964 en la revista Civitas y estaba enfocado hacia algunas figuras de primer plano del partido italiano (Sturzo, De Gasperi, etc.), en el concepto de democracia y en los principales postulados democratacristianos. Como parlamentario democratacristiano, Taviani fue varias veces ministro (Defensa, Hacienda, Interior). 
“el ejemplo chileno demostró que la verdadera revolución se obtiene sin violencia, reforzando las instituciones democráticas, removiendo los obstáculos que se oponen al desarrollo de la cultura, realizando una amplia intervención pública en economía y restando a las presiones extranjeras los recursos naturales propios" 155 .

Bernassola no vislumbraba que la experiencia de la DC chilena y del gobierno de Frei se habría extinguido luego de dos años, ni menos que en 1973 los democratacristianos chilenos no se habrían opuesto al golpe. Mucho se escribió, sobre todo en tono polémico, sobre las responsabilidades del PDC en esas circunstancias ${ }^{156}$. Por razones de espacio no es posible afrontar el tema aquí. Solo se puede acotar, a modo de conclusión, y en el marco de las relaciones ítalo-chilenas, que la DCI oficialmente se mostró sorprendida por el golpe de Estado y que las relaciones interpartidistas sufrieron un brusco enfriamiento en los dos años posteriores a la subida al poder de los militares, como lo demuestra la conocida carta de Eduardo Frei a Mariano Rumor de noviembre de $1973^{157}$, en la cual el líder chileno justificaba su conducta y la de su partido en ocasión del derrocamiento de Allende y desmentía acuerdos con los militares, para volverse nuevamente cordiales en el bienio 1975-76; y que en el plano de las relaciones diplomáticas, Italia fue uno de los pocos países que no reconoció a la Junta Militar. Solo con respecto a la dictadura chilena, el gobierno italiano optó por la línea de la firmeza, sobre todo por estar obligado por motivaciones contingentes ligadas a la política nacional (intransigencia de los socialistas) $)^{158}$. Hacia las otras dictaduras militares en el poder en esos años, Roma adoptó otra conducta, tendiente a no cometer los mismos "errores" anteriores con ocasión del cambio de régimen en Chile en 1973, prefiriendo una consciente y sustancial indiferencia hacia los sucesos políticos internos.

155 Bernassola, op. cit., 35.

156 En este sentido, ver, escrito en italiano y sobre la ola emocional por la trágica noticia de la muerte de Salvador Allende y el fin de la experiencia política de la Unidad Popular (además de las primeras noticias con respecto a la violación de los derechos humanos), el ya mencionado homenaje de Corrado Corghi (L'ideologia democristiana e l'internazionale DC), según el cual, a propósito del rol de la Internacional democratacristiana y de la DC chilena en la ocasión del golpe, "la fase de su historia que ella ha cerrado con el sangriento golpe de Estado en Chile, presenta una larga lista de ilusiones, de astucias, de fracasos y también de algunos serviles arreglos". Ibid., 277.

157 La versión original se encuentra en el Centro de documentación Fundación Frei. Una reproducción integral se encuentra en el libro de Sofía Correa et al., Documentos del siglo XX chileno, Santiago, Editorial Sudamericana, 2001, 413-427.

158 Raffaele Nocera, "Il governo italiano e la DC di fronte al golpe cileno", en Nuova Storia Contemporanea 2, Firenze, marzo-abril de 2008, 87-110. 